\title{
The Effect of Cross Flow on Slat Noise
}

\author{
David P. Lockard* and Meelan M. Choudhari ${ }^{\dagger}$ \\ NASA Langley Research Center, Hampton, VA 23681
}

\begin{abstract}
This paper continues the computational examination (AIAA Journal, Vol. 45, No. 9, 2007, pp. 2174-2186) of the unsteady flow within the slat cove region of a multi-element high-lift airfoil configuration. Two simulations have been performed to examine the effect of cross flow on the near-field fluctuations and far-field acoustics. The cross flow was imposed by changing the free-stream velocity vector and modifying the Reynolds number. The cross flow does appear to alter the dynamics in the cove region, but the impact on the noise seems to be more dependent on the flow conditions. However, separating out the true effects of the cross flow from those of the Mach and Reynolds number would require additional calculations to isolate those effects.
\end{abstract}

\section{Nomenclature}

$\begin{array}{ll}a & \text { speed of sound } \\ c & \text { stowed chord } \\ c_{s} & \text { slat chord } \\ f & \text { frequency } \\ M & \text { Mach number, }\left|\mathbf{V}_{o}\right| / a_{o} \\ p & \text { pressure } \\ \operatorname{Re}_{c} & \text { Reynolds number, }\left|\mathbf{V}_{o}\right| c / \nu_{o} \\ S t & \text { Strouhal number, } f^{*} c_{s} / U_{o} \\ u, v, w & \text { Cartesian fluid velocity components } \\ U, V, W & \text { time-averaged velocity components } \\ |\mathbf{V}| & \text { magnitude of velocity vector } \\ x, y, z & \text { Cartesian coordinates }\end{array}$

\author{
Greek: \\ $\rho \quad$ fluid density \\ $\beta \quad$ yaw angle
}

\section{Superscript:}

' perturbation quantity (e.g. $\rho^{\prime}=\rho-\rho_{\infty}$ )

* dimensional quantity

$\begin{array}{ll}\text { Subscript: } \\ \infty & \text { dimensionless free-stream quantity } \\ o & \text { dimensional free-stream reference quantity }\end{array}$

\section{Introduction}

The non-propulsive (or airframe) sources of aircraft noise include high-lift devices (i.e., leading-edge slat and trailing-edge flaps) and the aircraft undercarriage. The ranking of these sources is configuration dependent; however, both model scale tests ${ }^{1-6}$ and flyover noise measurements ${ }^{7}$ have identified the leading-edge slat as a prominent source of airframe noise during aircraft approach. The slat noise spectrum is typically broadband, but may include one or more narrower peaks associated with aerodynamic and/or aeroacoustic resonances. Previous measurements indicate that the broadband spectrum has a maximum near Strouhal numbers between 1 to 3 (where the Strouhal number $=f^{*} c_{s} /\left|\mathbf{V}_{o}\right|$ is based on the free-stream velocity $\left|\mathbf{V}_{o}\right|$ and slat chord $c_{s}$ ), and exhibits a peak in the directivity in the lower aft quadrant at the corresponding frequency. ${ }^{8}$ The overall sound pressure level (OASPL) for slat noise sources has been noted to scale with $M^{4.5}$ by Dobrzynksi ${ }^{8}$ and $M^{5}$ by Guo, ${ }^{9,10}$ where $M$ denotes the free-stream or flight Mach number. Mendoza ${ }^{6}$ found that the overall sound pressure level scaled with $M^{5}$, but with something between $M^{4}$ and $M^{5}$ in the range of mid to high frequencies. However, as discussed in Refs. 8 and 10, the physical mechanisms underlying the observed characteristics of slat noise have not been fully explained as yet.

An essential ingredient to developing physics-based predictions of airframe noise involves synergistic combinations of experiments and numerical simulations for subcomponents. Recent studies of this type have provided a number of useful physical insights into the noise source mechanisms that are responsible for the dominant features of the measured slat- and flap-noise spectra. Specifically, the high-frequency spectral hump in the slat noise measurements at NASA ${ }^{2,5}$ has been attributed to vortex shedding from a finite thickness slat trailing edge. ${ }^{11,12}$ The broadband component of slat noise at lower frequencies has been linked with the interaction between unsteady vortical structures in the slat cove region and the adjacent features of the high-lift geometry (viz., the slat trailing edge and the gap region between the slat and the main element). ${ }^{13-15}$ The 2-D computations of this type helped clarify the cause-effect relationships between the near-field flow structures and the far-field noise; however, a further assessment of these computations ${ }^{16}$ indicated

\footnotetext{
*Aerospace Technologist, Computational AeroSciences Branch, Mail Stop 128, Senior Member, AIAA

${ }^{\dagger}$ Aerospace Technologist, Computational AeroSciences Branch, Mail Stop 128, Associate Fellow, AIAA

This material is declared a work of the U.S. Government and is not subject to copyright protection in the United States.
} 
excessively energetic vortical structures in comparison with the PIV measurements. ${ }^{17}$ 3-D computations over a narrow portion of the model span ${ }^{18}$ led to significant improvement in that regard, yielding a favorable comparison with the PIV measurements. ${ }^{17}$ The importance of 3-D fluctuations in determining the unsteady dynamics within the cove region has also been confirmed via computations for other high-lift configurations and using alternative numerical algorithms. ${ }^{19,20}$

The acoustic sources in the slat cove have been investigated experimentally ${ }^{17}$ using the $30 \mathrm{P} / 30 \mathrm{~N}$ model. The $30 \mathrm{P} / 30 \mathrm{~N}$ model tested in the Basic Aerodynamic Research Tunnel (BART) at NASA Langley Research Center represents a generic, three-element, zero-sweep high-lift configuration with slat and flap deflections of 30 degrees each. The slat chord and flap chord of the model are equal to $15 \%$ and $30 \%$, respectively, of the stowed chord of 18 in $(0.457 \mathrm{~m})$. For the approach configuration, the slat gap is $2.95 \%$; the flap gap is $1.27 \%$; and the slat and flap overhang settings are equal to $-2.95 \%$ and $0.25 \%$ of the stowed chord, respectively. Reference 21 provides a definition of these rigging parameters. At the test Mach number of $M=0.17$, the Reynolds number, $\operatorname{Re}_{c}$, based on the stowed chord of the BART model, corresponds to 1.71 million. While this Reynolds number is substantially lower in comparison with full-scale applications, the BART experiment is still suitable for validating numerical predictions of the slat cove noise sources as described in Ref. 18. The BART measurements ${ }^{17}$ consist of steady surface pressure measurements, plus extensive 2-D particle image velocimetry (PIV) data within the mid-span plane of the model.

The effect of the spanwise extent of the computational domain was investigated by Lockard and Choudhari ${ }^{22}$ by increasing the span from 1" (37.3\% of the slat chord as used in Ref. 18) to 6" (226\% of the slat chord or $15 \%$ of the model span) while maintaining the same spanwise resolution. The simulations with the longer span indicated that the spanwise surface pressure correlations do not become smaller than 0.05 until around 2" (74.6\% of the slat chord). The long span also enabled predictions of the far-field noise without excessive assumptions about the near-field spanwise behavior. However, the spanwise correlation length of the acoustic signals was found to be on the order of a slat chord, so a much longer span than even $226 \% c_{s}$ would be needed to completely capture the radiated acoustics of the frequencies near the peak in the broadband signal. Nonetheless, the near-field unsteadiness that gives rise to the noise can be adequately modeled with a 2" span, allowing the shorter span to be used in parametric studies examining the source mechanism.

Although the slat geometry is basically two dimensional (2D), most modern aircraft have swept wings which will produce a spanwise flow. The effect of the cross flow on slat noise has not been thoroughly investigated. A laminar mean flow is independent of sweep as long as the planar parameters are the same; however, the instantaneous fluctuations, and corresponding turbulence dynamics, can be affected by sweep. Hence, cross flow could potentially alter the fluctuations in the slat cove shear layer which are believed to be responsible for the broadband portion of the slat spectrum. A majority of experimental investigations of slat noise, and nearly all computational simulations, have concentrated on 2-D, unswept models. Although the noise from swept wings with slats has been measured in several tests, no equivalent unswept configuration has been examined with the same high-lift, cross-section geometry. Imamura et $\mathrm{al}^{23}$ did perform simulations of both swept and unswept wing configurations, but their results were inconclusive as to the effect of the cross flow because the observed differences were deemed to be within their uncertainty. Furthermore, they only measured a fully 3-D configuration with sweep, so other effects were included beyond those modeled in the periodic simulations.

The current effort seeks to computationally examine the effect of sweep by imposing a spanwise flow in the 30P/30N configuration. Sweep effects can be manifested in multiple ways within the hydrodynamics and acoustics, and this paper only represents a first step in examining them. Based on the spanwise correlation results of Ref. 22, a spanwise extent of 2" (74.6\% of the slat chord) is used in the simulations. Because of the ambiguity in what free-stream velocities and Reynolds numbers should be specified to maintain some relation to the baseline case, two cases with an imposed spanwise flow will be used. The conditions are summarized in Table 1. The velocities in the table and this paper are nondimensionalized by the free-stream speed of sound, and, therefore are equivalent to Mach numbers. The baseline Case 1 has a Mach number of 0.17 and a Reynolds number based on the stowed wing chord of 1.71 million. This duplicates the conditions of the computations in Ref. 22 and will serve to evaluate the sufficiency of using a shorter span in the current simulations. The grid system for Case 2 is unchanged from Case 1, but the free-stream velocity vector is rotated so that it is no longer normal to the leading edge. Case 2 has the same incoming velocity normal to the leading edge, $U_{\infty}$, as the baseline, but the total free-stream Mach number is increased to 0.208 with a yaw angle of $\beta=35.26^{\circ}$ to produce a spanwise flow of $W_{\infty}=0.1202$. Hence, the effective chord is increased, and the Reynolds number is changed to 1.396 million to try to maintain the same viscous characteristics in the $x-y$ plane as in Case 1 . For Case 3 the free-stream velocity magnitude is 0.17 , but with a yaw flow angle of $\beta=45^{\circ}$. The spanwise flow is 0.1202 as in Case 2, but $U_{\infty}$ decreases to 0.1202. Neglecting the spanwise flow and using Blasius similarity arguments leads to a Reynolds number of 2.4183 million to account for the reduced $U_{\infty}$. 


\begin{tabular}{|c||c|c|c|c|c|}
\hline & $\left|\mathbf{V}_{\infty}\right|$ & $\beta$ & $U_{\infty}$ & $W_{\infty}$ & $R e_{c} \times 10^{-6}$ \\
\hline \hline Case 1 & 0.17 & $0^{\circ}$ & 0.17 & 0.0 & 1.71 \\
\hline Case 2 & 0.208 & $35.26^{\circ}$ & 0.17 & 0.1202 & 1.396 \\
\hline Case 3 & 0.17 & $45^{\circ}$ & 0.1202 & 0.1202 & 2.4183 \\
\hline
\end{tabular}

Table 1. Case definitions.

\section{Computational Simulations}

The computational procedure closely follows that used during the simulations in Refs. 18 and 22. Version 6 of the CFL3D ${ }^{24}$ flow solver developed at NASA Langley Research Center is used to solve the 3-D, time-dependent, Reynoldsaveraged Navier-Stokes (RANS) equations using a finite-volume formulation; the full viscous fluxes in all three grid coordinates were retained during the present simulations. The simulations used a third-order upwind scheme with fluxdifference splitting, which has been shown to provide second order spatial accuracy in previous applications of CFL3D. ${ }^{24}$

\section{II.A. Configurations and Grids}

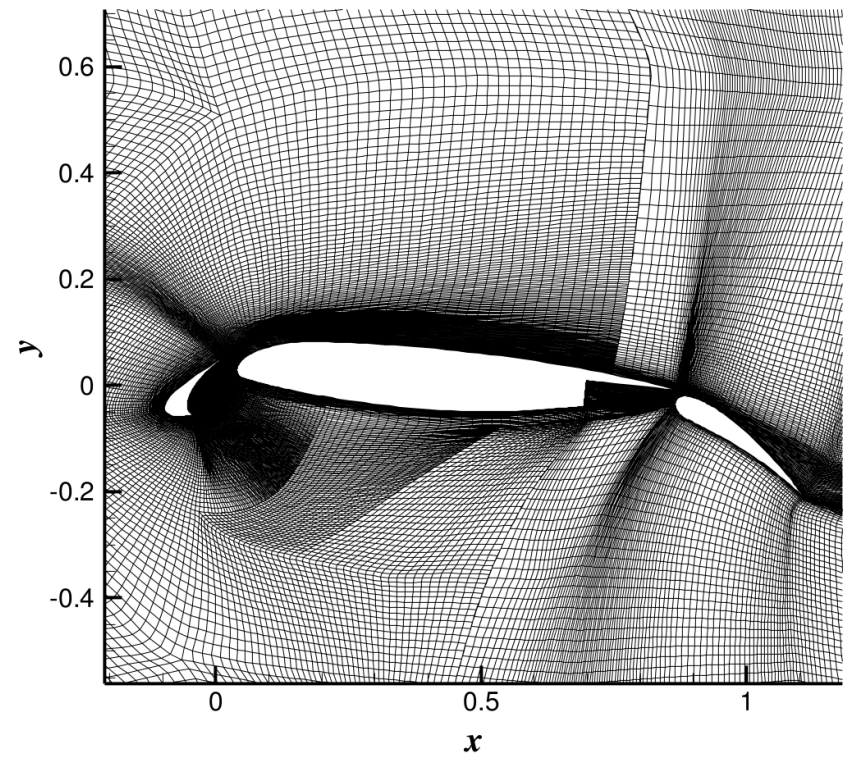

Figure 1. Planar view of grid (every other point).

The $30 \mathrm{P} / 30 \mathrm{~N}^{21}$ high-lift system was simulated in free air without any of the wind-tunnel walls. The trailing edge of each of the three elements has a finite thickness. However, following the approach taken in Ref. 22 for computational efficiency, all of the trailing edges (including the cusp or first edge of the slat) were artificially sharpened while preserving the camber of the respective sections. Based on previous studies, ${ }^{11,12}$ sharpening the trailing-edge should only affect vortex shedding caused by trailing-edge bluntness and not the cove dynamics. Sharpening the cusp on the slat has little effect on the cove shear layer because the cusp is merely serving as a fixed separation point like the corner of a backward facing step. As the focus of the current study is the broadband noise source associated with the slat shear layer, removing points around the edges allowed additional grid points to resolve the slat cove dynamics and near-field acoustics. The investigated configuration corresponds to $4^{\circ}$ angle of attack in BART, ${ }^{17}$ which approximates the mean slat loading for a free-flight configuration at $5.5^{\circ}$ angle of attack. Considerable effort was spent in grid generation to allow adequate resolution of the relevant aerodynamic and acoustic phenomena in an efficient manner. The block structured, $x-y$ planar grid shown in Fig. 1 contained a total of 563,741 points in 77 blocks. Care was taken so that the first point off the solid surfaces was at $y^{+} \sim O(1)$. To generate the 3-D grids, the planar mesh was replicated along the span over a distance of 0.747 slat chords using 129 points for a total grid point count of 62 million. Most of the block interfaces are point-matched with a one-to-one correspondence from each side. However, patched interfaces, where the grid is coarsened going from one block to its neighbor, were employed but restricted to regions away from the slat. The planar 
grid and spanwise grid spacing are identical to that used in Ref. 22, and they are based on the grid resolution studies in Ref. 18.

Characteristic boundary conditions were used along the far-field boundaries in the $x-y$ plane, except for extrapolation from the interior at the downstream boundary. The circular outer boundary was located 12 airfoil chords from a point in the slat cove. Periodic boundary conditions were used across the spanwise boundaries of the computational domain. No attempt was made to resolve the end effects associated with the presence of tunnel side walls in the experiments. No-slip conditions were imposed at the solid surfaces, along with an adiabatic wall thermal boundary condition.

The two-equation Shear Stress Transport (SST) model of Menter ${ }^{25}$ is used to capture the mean flow behavior of the unresolved scales of motion in regions away from the slat cove region, whereas the turbulence production term in the turbulence transport equations was switched off within the cove region ${ }^{18}$ to eliminate the excessive diffusive effects of the turbulence model on the resolved unsteady flow structures. Due to a lack of experimental transition data along the solid surfaces, as well as to maintain consistency with the previous 2-D simulations, ${ }^{14-16}$ the flow within the RANS regions was treated as fully turbulent, allowing the boundary layer transition locations along all three elements to be determined by the SST turbulence model.

CFL3D employs a dual-time-stepping algorithm with subiterations used to converge the solution within each time step. Fifteen subiterations were used per time step to reduce the residual by a minimum of three orders of magnitude. The time step was $d t^{*} a_{o} / c=0.0016464$ or $d t^{*}\left|\mathbf{V}_{\mathbf{o}}\right| / c=0.00968$. The corresponding convective scale for a particle traveling with the flow to traverse the stowed chord of the airfoil is 3573 time steps. The time step used in the current simulations is larger than those used in some earlier studies of the $30 \mathrm{P} / 30 \mathrm{~N}$ configuration ${ }^{16,18}$ because the trailing-edges have been sharpened to avoid having to resolve the small trailing-edge thickness that would have enabled the simulations to capture any high-frequency vortex shedding behind the edges. Based on the time-step study performed in Ref. 22, the step size used in the current simulations should be sufficient to resolve the broadband component of the slat fluctuations which is the focus of the present study.

The simulation procedure includes several steps. First, a steady-state computation was used to set up the basic mean flow, followed by an unsteady calculation with random suction and blowing applied to different spanwise and azimuthal sections of the slat in order to accelerate the onset of 3D, unsteady flow structures. The forcing did not exceed 3\% of the freestream velocity. The forcing was turned off after significant unsteadiness was observed, typically a few hundred time steps into the unsteady calculation. The simulation was then run for 30,000 time steps to allow the transient flow field to wash out before collecting time records. A slightly different procedure was used initiate unsteadiness in Refs. 18 and 22, and the favorable agreement in the near-field unsteadiness between these simulations seems to indicate a relative insensitivity of the results to how the initial transients are generated. After this phase, well-resolved, unsteady structures develop in the slat cove region. There is also some unsteadiness associated with a separated region on the flap. The grid is too coarse to resolve the unsteady flow around the flap, and these fluctuations eventually settle down to levels that do not significantly impact the slat cove region. In the real flow, the oscillations in the flap separated region are probably persistent and much stronger, but the purpose of the current study is to isolate the slat cove dynamics. Therefore, the observed damping behavior in the flap region is actually intended and advantageous. Averaged flow quantities were produced by time-averaging over 35,000 time steps. To increase the number of averages, a second averaging process was performed in the spanwise direction. Although shear layers can exhibit inhomogeneous spanwise behavior over the relatively large length scales corresponding to the wavelength of the dominant acoustic frequencies, spanwise homogeneity of the flow statistics is a reasonable assumption.

\section{Results}

The streamlines within the $x-y$ plane in the vicinity of the slat element are shown in the Fig. 2. The streamlines were generated by neglecting the spanwise component of the flow. The expected recirculation zone in the slat cove is seen in the results of all three simulations. Although slight differences can be identified, the planar flow pattern is basically the same when the spanwise flow is imposed. Figure 3 shows two distributions of the $u$ velocity as a function of vertical distance (normalized by the wing chord) at the streamwise location of the slat cusp, excluding the recirculation region in the cove. The locations of the two cuts are shown as the vertical purple lines in Figure 3(a). Figure 3(a) shows the profiles on the suction side of the airfoil, and Fig. 3(b) presents the distributions on the pressure side. The profiles are relatively similar between the three cases, but the cases with cross flow are in better agreement on the suction side. On the pressure side, Cases 1 and 3 agree the best. The boundary layer profiles appear to confirm that, although not identical, all three cases have similar viscous effects in the $x-y$ plane.

The coefficient of pressure, $C_{p}=2\left(p^{*}-p_{o}\right) /\left(\rho_{o}\left|\mathbf{V}_{\mathbf{o}}\right|^{\mathbf{2}}\right)$, on the high-lift system is presented in Fig. 4 . The results from all three calculations are included. The data was generated by averaging over time, then averaging over the span by 


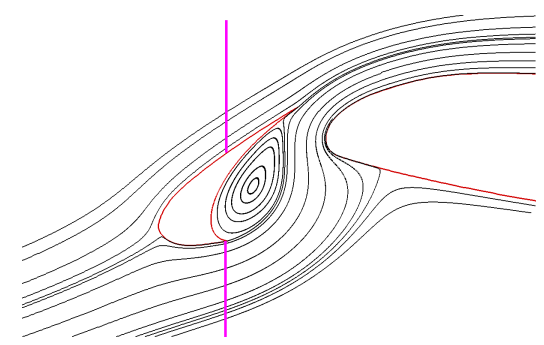

(a) $\left|\mathbf{V}_{\infty}\right|=0.17, \beta=0^{\circ}$

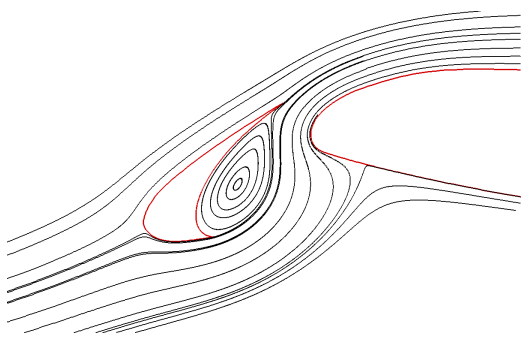

(b) $\left|\mathbf{V}_{\infty}\right|=0.21, \beta=35^{\circ}$

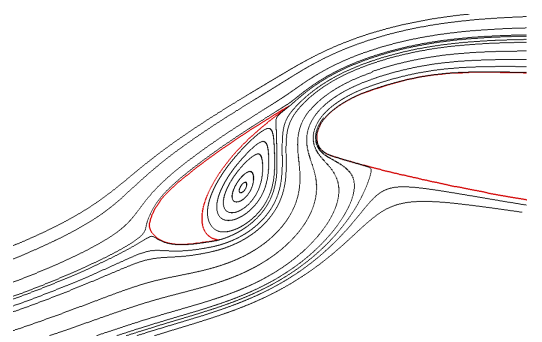

(c) $\left|\mathbf{V}_{\infty}\right|=0.17, \beta=45^{\circ}$

Figure 2. Streamlines around the airfoil.

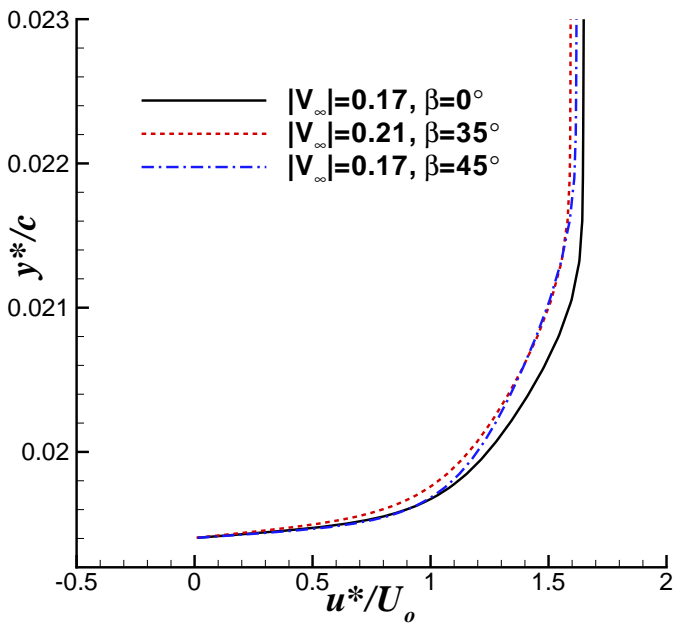

(a) Above slat

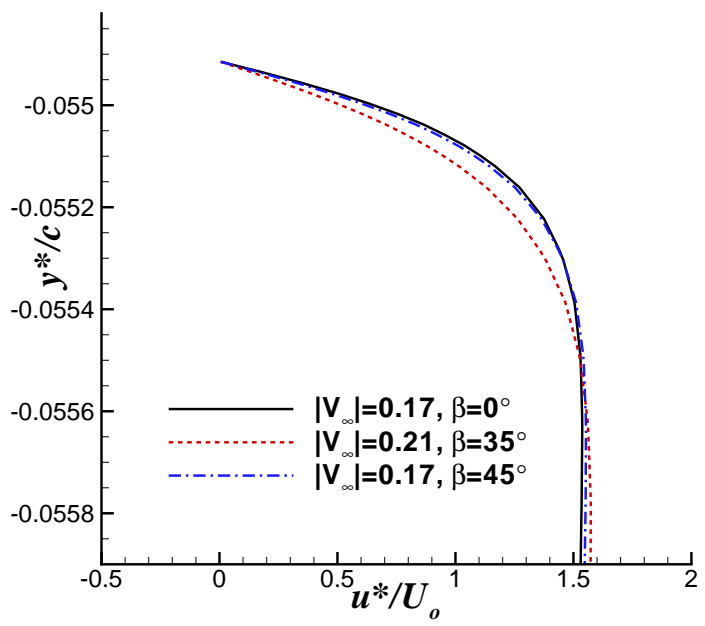

(b) Below slat

Figure 3. Velocity profiles at the streamwise position of the slat cusp.

assuming the flow is basically homogeneous in that direction. The slight jump on the pressure side at $x / c=0.7$ is caused by the geometric discontinuity where the flap cove begins. Using the total velocity as the reference in the definition of the coefficient of pressure does not collapse the curves. However, if only the velocity normal to the leading edge, $U_{o}$, is used in the definition of $C_{p}$, the results from all three simulations are in reasonable agreement as seen in Fig. 5. For this 2-D geometry, the spanwise flow is basically passive as far as the lift is concerned. As expected, the $C_{p}$ distribution is basically described by the planar, inviscid flow and is relatively insensitive to sweep. However, the spanwise flow does have some minimal effect on the location of the separation on the flap which then influences the overall circulation.

In the calculations in Ref. 22 , the total lift on the high-lift system drifted by $2 \%$ during the calculation because the separation on the flap was very slow to establish a quasi-steady state. The drift was minimized in the current simulations by running the cases longer before starting sampling. To further reduce the effect of any drift in the fluctuating pressure levels, the root-mean-square (rms) levels were calculated over segments of 2400 time steps. Over each of these segments, the perturbations were calculated relative to the short-time mean for the segment. A subsequent average was performed over rms levels from all of these segments. A comparison of the calculated $C p_{r m s}^{\prime}$ is shown in Fig. 6. The peak around $x / c=0.85$ is associated with a very localized region of unsteadiness at the trailing edge of the main element. Although the grid is relatively coarse in the flap cove, there is still some unsteadiness that develops and interacts with the edge. Although the spike at the flap trailing edge is quite high, the area that sees high fluctuation levels is quite small, so the overall impact on the radiated noise is expected to be small. As was the case for $C_{p}$, normalizing using the total freestream velocity does not collapse the curves. A close-up of the $C p_{r m s}^{\prime}$ field on the slat when $U_{o}$ is used as the reference velocity in the definition of $C_{p}$ is shown in Fig. 7. Both of the simulations with the spanwise flow collapse fairly well and exhibit slightly higher fluctuation levels in the slat cove region than the baseline case. Presumably, the longer flow path from the cusp to the cove reattachment point for the cases with the spanwise flow gives instabilities growing on the slat shear layer longer to develop. The waves may also be more unstable in the presence of a cross flow as was found by $\mathrm{Li}$ and Lele ${ }^{26}$ for skewed compressible mixing layers.

The magnitude of the planar velocity, nondimensionalized by $U_{o}$, is compared in Fig. 8. Some slight differences can be seen in the cove near the cusp, but the velocity distributions are quite similar for all three computations. The trajectory 


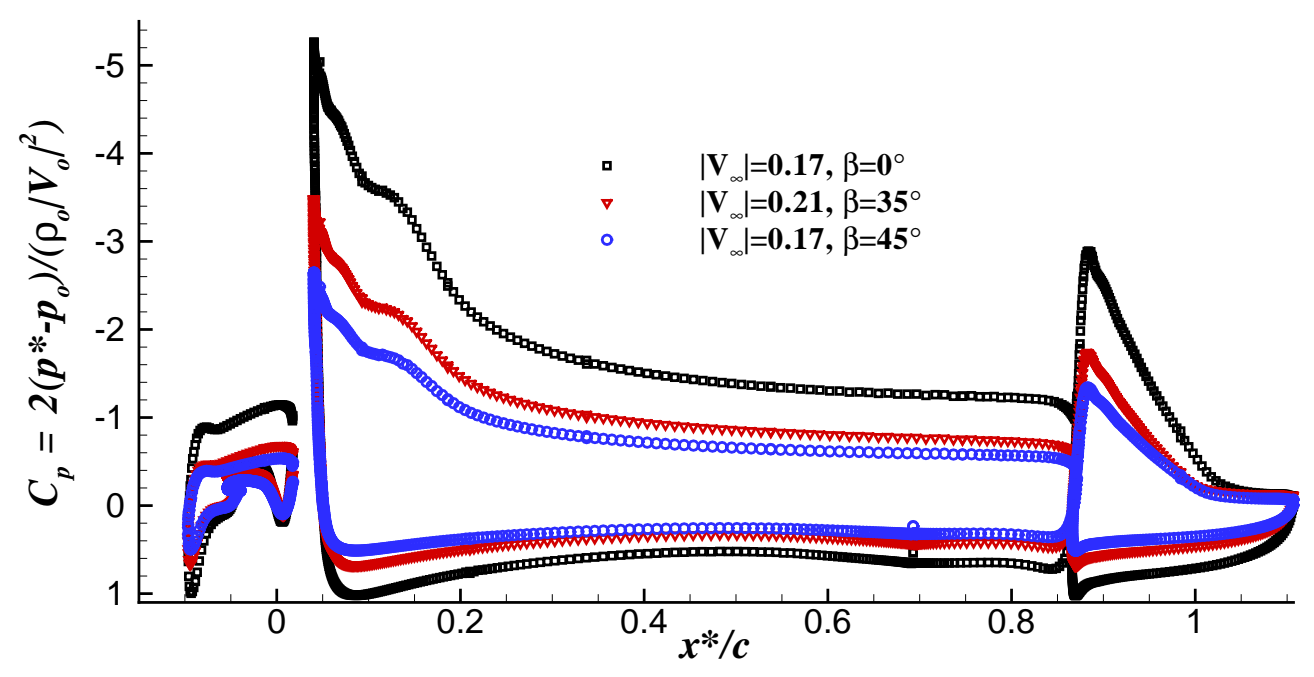

Figure 4. Coefficient of pressure on the airfoil using $\left|V_{0}\right|$ as the reference velocity.

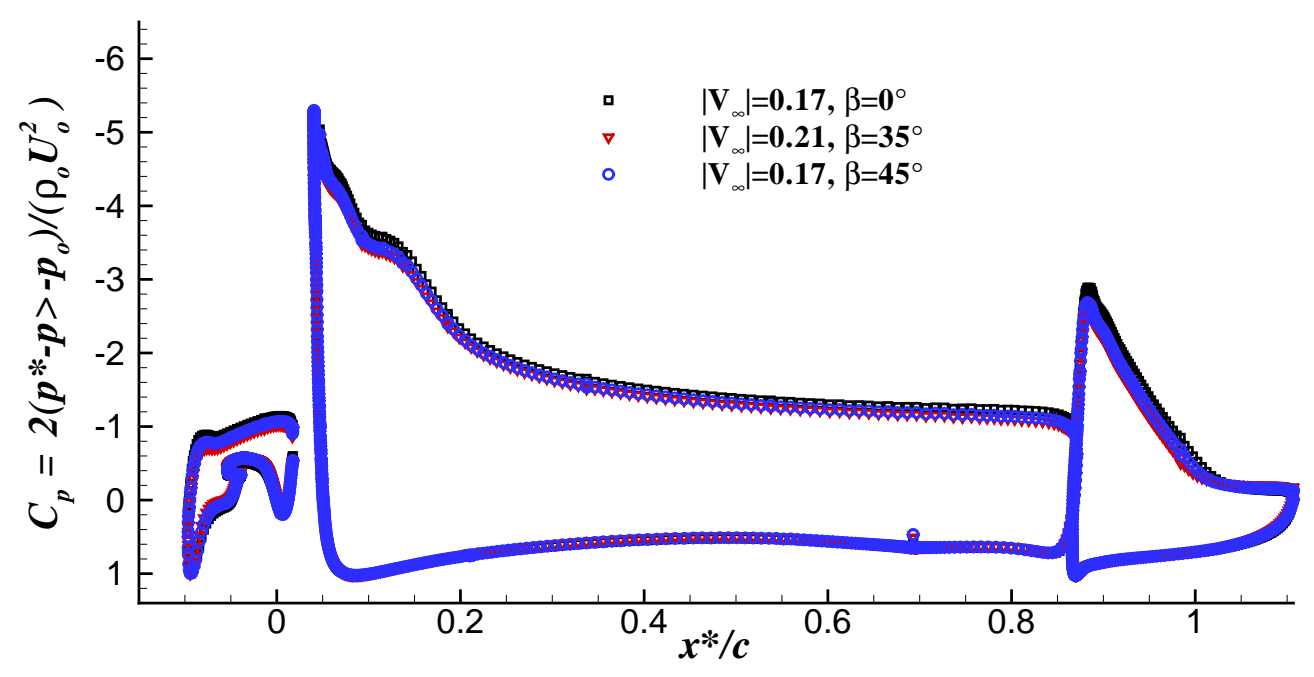

Figure 5. Coefficient of pressure on the airfoil using $U_{o}$ as the reference velocity.

of the shear layer, shown as the purple line, and the reattachment point on the lower surface of the slat are nearly identical in all cases. Similarly, the spanwise vorticity, $\omega_{z}^{*} c / U_{o}$, in Fig. 9 shows that the strength of the shear layer in the cove is the same regardless of the spanwise flow. However, the 3-D turbulence kinetic energy, $\frac{1}{2}\left(<u^{\prime} u^{\prime}\right\rangle+\left\langle v^{\prime} v^{\prime}\right\rangle+<$ $w^{\prime} w^{\prime}>$ ), normalized by the square of the free-stream velocity, $U_{o}^{2}$, does reveal some differences as seen in Fig. 10. The thin region of high 3-D TKE near the reattachment point and extending to the trailing edge is more pronounced in the two simulations with the spanwise flow. The spanwise fluctuations are primarily responsible for the high TKE in this region. Just below this region is another, larger area of enhanced TKE where the vertical velocity fluctuations peak. Here, the value of the 3-D TKE is slightly lower for the $\left|\mathbf{V}_{\infty}\right|=0.17, \beta=45^{\circ}$ simulation (Fig. 10(c)). The elevated TKE levels are caused by instabilities in the cove shear layer being rapidly distorted as they approach the underside of the slat. Some other differences between the three cases are evident such as the region of low TKE in the cove (indicated by the blue regions) being more pronounced for the case without a spanwise flow (Fig. 10(a)). Nonetheless, the primary characteristics of all three 3-D TKE distributions are similar.

The time-averaged quantities have been found to be in reasonable agreement between the three calculations when the velocity normal to the leading edge is used as the reference velocity. Similar agreement has not been obtained for the spectral information. The power spectral density of the surface pressure at the 6 points identified in Fig. 8 are presented in Fig. 11. The amplitude has been adjusted assuming $p=p^{*} /\left(\rho_{o} a_{o}^{2}\right) \sim U_{\infty}^{2}$ as this produced a reasonable collapse 


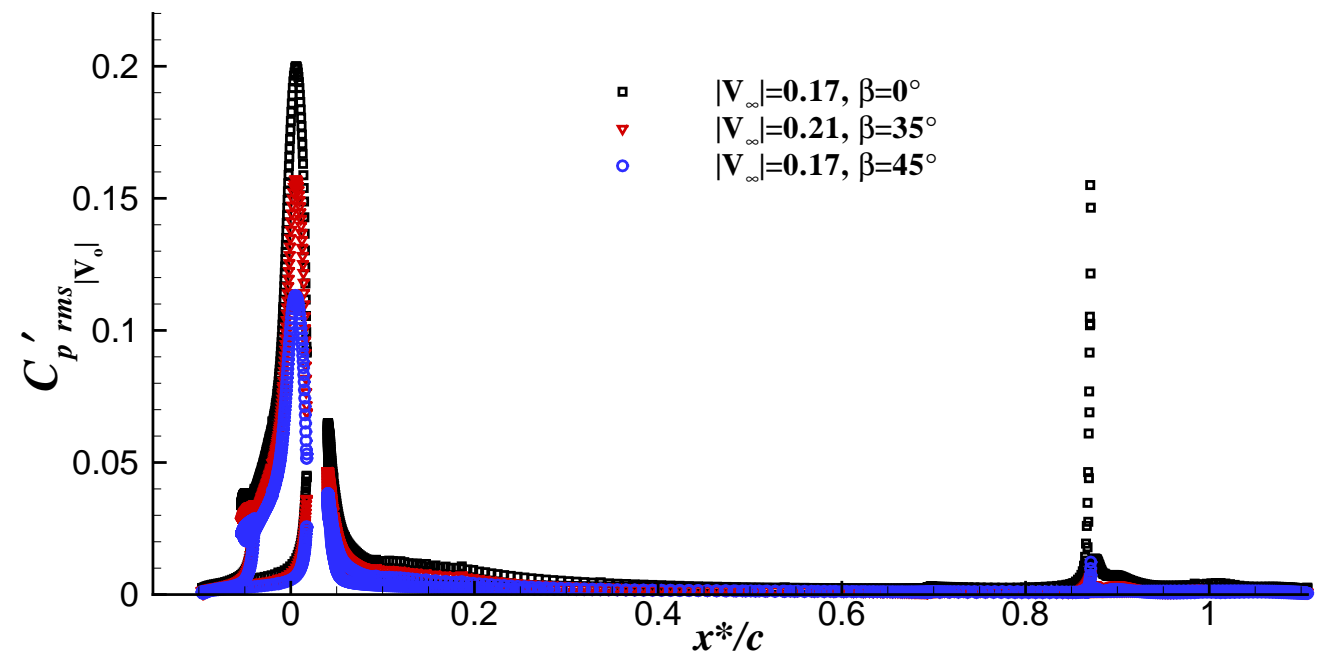

Figure 6. Fluctuating $C_{p}^{\prime}$ on the airfoil using $\left|\mathbf{V}_{\mathbf{o}}\right|$ as the reference velocity

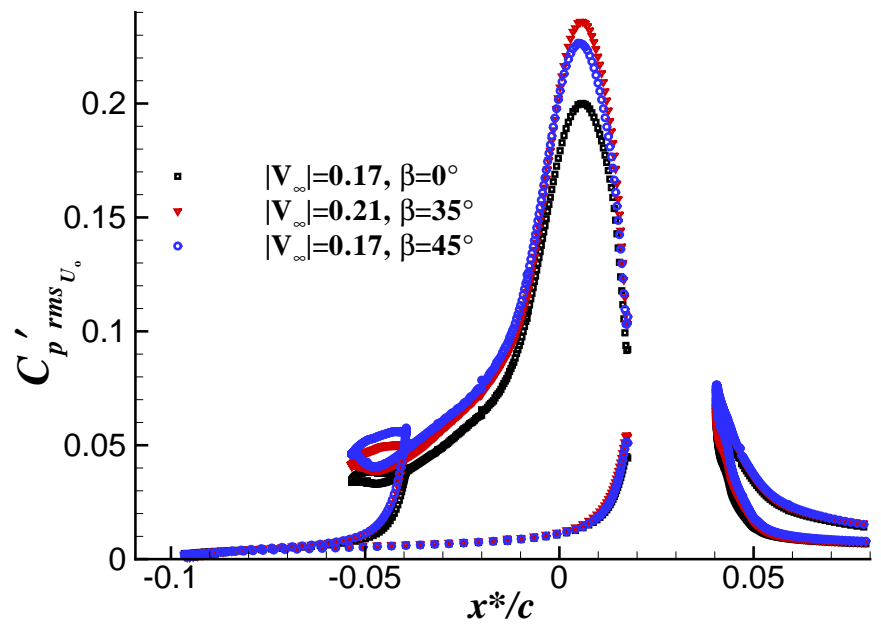

Figure 7. Fluctuating $C_{p}^{\prime}$ on the slat using $U_{o}$ as the reference velocity.

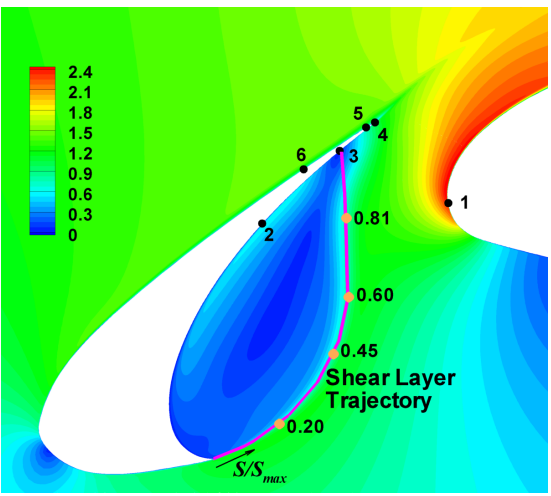

(a) $\left|\mathbf{V}_{\infty}\right|=0.17, \beta=0^{\circ}$

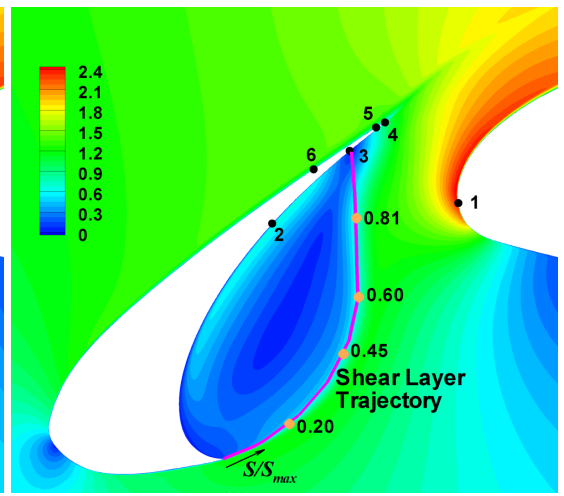

(b) $\left|\mathbf{V}_{\infty}\right|=0.21, \beta=35^{\circ}$

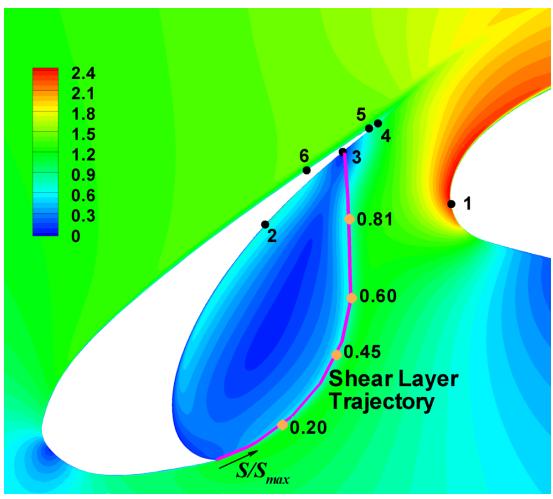

(c) $\left|\mathbf{V}_{\infty}\right|=0.17, \beta=45^{\circ}$

Figure 8. Magnitude of the planar velocity, $\left|\mathbf{V}_{2 D}^{*}\right| / U_{o}$, around the slat averaged both temporally and in the spanwise direction. $S$ is the distance along the shear layer trajectory, and $S / S_{\max }=\mathbf{0 . 2 1}, 0.45,0.60,0.82$ correspond to four points in the shear layer that will be examined. The surface pressure at the points numbered 1 to 5 will also be examined. 


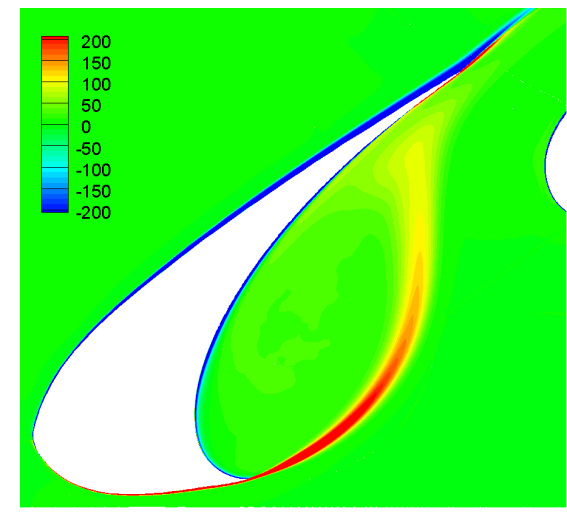

(a) $\left|\mathbf{V}_{\infty}\right|=0.17, \beta=0^{\circ}$

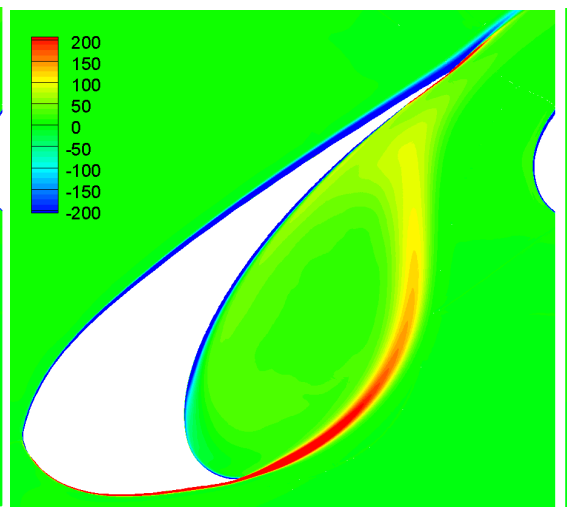

(b) $\left|\mathbf{V}_{\infty}\right|=0.21, \beta=35^{\circ}$

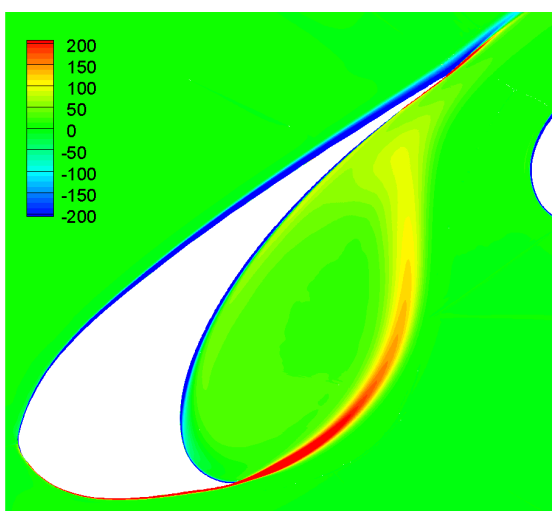

(c) $\left|\mathbf{V}_{\infty}\right|=0.17, \beta=45^{\circ}$

Figure 9. Spanwise vorticity, $\omega_{z}^{*} c / U_{o}$, around the slat averaged both temporally and in the spanwise direction.

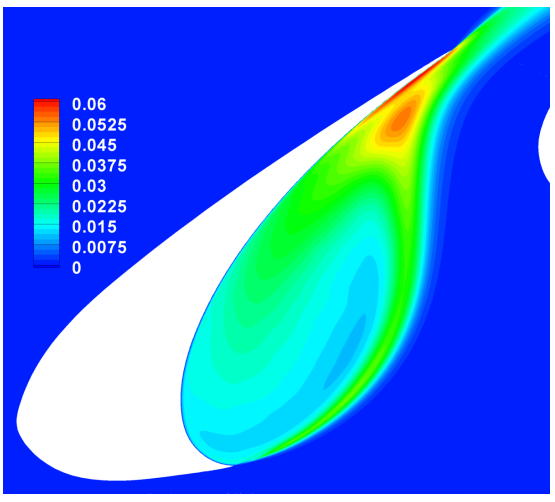

(a) $\left|\mathbf{V}_{\infty}\right|=0.17, \beta=0^{\circ}$

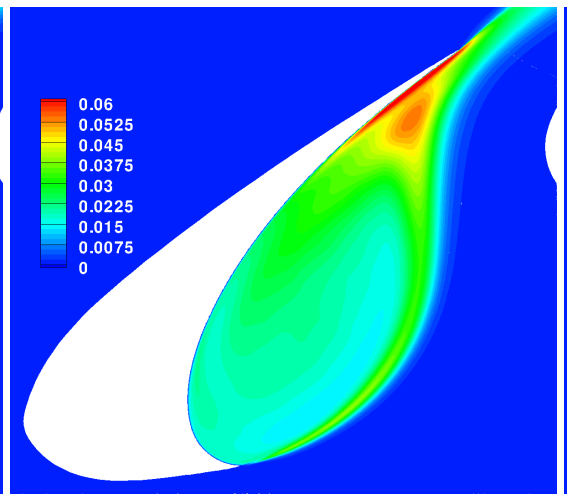

(b) $\left|\mathbf{V}_{\infty}\right|=0.21, \beta=35^{\circ}$

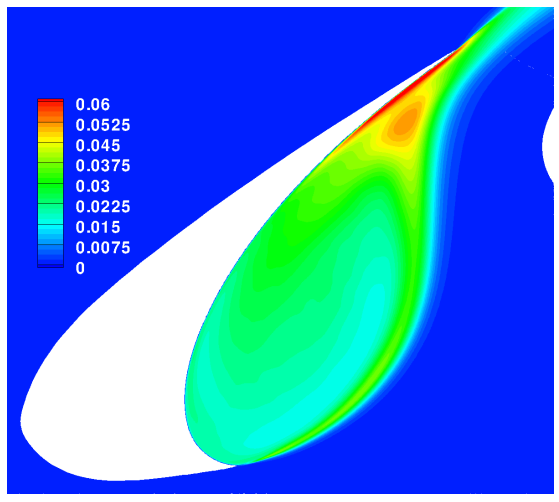

(c) $\left|\mathbf{V}_{\infty}\right|=0.17, \beta=45^{\circ}$

Figure 10. 3-D Turbulence kinetic energy normalized by $U_{o}^{2}$ around the slat averaged both temporally and in the spanwise direction.

of the rms data. The reference velocity is $U_{\text {ref }}=0.17$. The power spectral density is plotted against the the Strouhal number, $S t$, based on the free-stream velocity normal to the leading edge, $U_{o}$, and the slat chord, $c_{s}$. The results from the longer span calculation from Ref. 22 have also been included $\left(\left|\mathbf{V}_{\infty}\right|=0.17, \beta=0^{\circ}, z_{\max }=2.26 c_{s}\right)$, and the agreement with the current shorter span calculation is very good at all 6 locations. However, the Strouhal and amplitude scaling does not do a good job of collapsing the results from the calculations with a spanwise flow. At the two points that experience primarily acoustic fluctuations (Figs. 11(a) and (f)), the agreement might be considered reasonable in the higher frequencies above $S t=5$. The simulations do not attempt to resolve boundary layer unsteadiness in these regions, so any fluctuations are likely to be acoustics emanating from other locations. At these 2 points, the baseline $\left|\mathbf{V}_{\infty}\right|=0.17, \beta=0^{\circ}$ and $\left|\mathbf{V}_{\infty}\right|=0.21, \beta=35^{\circ}$ cases are in much better agreement with each other than with the case with $\left|\mathbf{V}_{\infty}\right|=0.17, \beta=45^{\circ}$. Note that the Strouhal scaling based on $U_{\infty}$ only shifts the $\left|\mathbf{V}_{\infty}\right|=0.17, \beta=45^{\circ}$ curve. For the other 4 points that are more directly influenced by the unsteadiness in the slat cove shear layer, the results of the 3 calculations diverge above a Strouhal number around 5. At these locations, the two cases with cross flow actually collapse quite well using the unscaled frequency as shown in Fig. 12(b)-(e). At point 5, the agreement is not quite as good, and this may be because the fluctuations on the upper surface near the trailing edge are a combination of acoustics and hydrodynamics. As seen in Fig. 12(a) and (f) for the two points seeing primarily acoustic fluctuations, the $\left|\mathbf{V}_{\infty}\right|=0.17, \beta=45^{\circ}$ case does not collapse with the other cases when using the unscaled frequency.

Obviously, the data can be scaled in many different ways to produce different levels of agreement between the three cases. However, the proper scaling does not appear to be straightforward nor consistent between the primarily hydrodynamic and acoustic fluctuations. Furthermore, different frequency ranges may be scaling differently as observed by Mendoza. ${ }^{6}$

A prominent feature that can be observed in the baseline spectra for points 1, 5, and 6 (Figs. 11 and 12) is a series of peaks between $S t=1$ to 5 or $f=800$ to $5000 \mathrm{~Hz}$. They are also prominent in the $\left|\mathbf{V}_{\infty}\right|=0.21, \beta=35^{\circ}$ case, but do not appear in the $\left|\mathbf{V}_{\infty}\right|=0.17, \beta=45^{\circ}$ case. The peaks are separated by approximately $700 \mathrm{~Hz}(\Delta S t=0.8)$, but 
the spacing varies by around $10 \%$. Furthermore, processing the data with a smaller bin width appears to reveal that each of the peaks is actually comprised of multiple peaks. The cause and nature of these peaks is unknown, but additional analysis of the data will hopefully reveal the physics behind this phenomena.

The spanwise correlation of the pressure near the reattachment point designated as point 3 in Fig. 8 is shown in Fig. 13(a). The spanwise coordinate is $z$, and the spanwise distance between two grid points with the same values of $x$ and $y$ is given by $\Delta z$. This spanwise distance is normalized by $c_{s}$ in the figure. For each $\Delta z / c_{s}$, the average value of the correlation is calculated for all grid point combinations with this separation distance. Because of the periodic boundary conditions, the correlation can only be computed for spanwise separations up to half the length of the computational span. In addition to the three new calculations, the result from the longer span calculation is included. At least for the locations examined, the spanwise correlation does not appear to be adversely affected by the shorter span used in the current set of computations. Furthermore, the spanwise correlation appears to be insensitive to the spanwise flow. However, the coherence at individual frequencies does reveal differences. As was shown in Ref. 22, the coherence at any frequency can be reasonably approximated by a Gaussian

$$
\gamma^{2}(f)=\exp \left[-\left(\frac{\Delta z}{L_{c}(f)}\right)^{2}\right]
$$

which allows the coherence information to be presented in terms of the coherence length scale $L_{c}(f)$. The parameter $L_{c}$ is determined for each frequency using a least-squares fit of the data. The coherence length normalized by the slat chord for point 3 is presented in Fig. 13(b). Although the baseline simulations with different span lengths are in excellent agreement, the coherence lengths for the 2 simulations with cross flow are much higher. The results for the cross-flow cases would actually exhibit peaks at the same frequencies if they were plotted against the unscaled frequency rather than the Strouhal number. The results for the 2 points on the upper surface of the slat are shown in Fig. 14. The fluctuations on the upper surface are caused by the interaction of the vortices from the cove shear layer interacting with the trailing edge of the slat, so examining this region should reveal the character of this interaction and presumably the radiated noise. At point 5 (Fig. 14(a)) the coherence length exhibits distinct peaks at multiple frequencies in all of the simulations except for the case with $\left|\mathbf{V}_{\infty}\right|=0.17, \beta=45^{\circ}$. At point 6 where the fluctuations are primarily acoustic, the agreement degrades because the acoustic wavelength is so long that the spanwise extent is insufficient. Nonetheless, the distinct peaks observed at point 5 are still quite evident. The cause of the different character of the coherence for the $\left|\mathbf{V}_{\infty}\right|=0.17, \beta=45^{\circ}$ case is unknown, but the lack of peaks in the spectra in Fig. 11(f) is likely connected.

Presumably the unsteady pressure signatures investigated at the points on the slat surface are related to the instabilities that grow in the slat cove shear layer. Therefore, examining the signals within the shear layer may help reveal if there is a connection between them. The velocity fluctuations in the cove at 4 points along the trajectory of the slat cove shear layer are investigated in Fig. 15. The distance along the trajectory, $S$, has been normalized by the total distance from the cusp to the reattachment point, $S_{\max }$. The fluctuation levels in $u$ are presented in the column on the left, and the fluctuations in $v$ are shown in the column on the right. Although not shown, the spectra of the pressure most closely resembles that of $u$ in shape. Although the autospectra of $u$ for the baseline case show distinct maxima that decreases in frequency as the shear layer spreads (Fig. 15(a)), the two cases with a spanwise flow have spectra that are relatively flat until they start to decay (Fig. 15(c) and (e)). Similarly to the surface pressure spectra, the velocity spectra in the cove region also exhibit a significant difference between the cases with and without a spanwise flow. Also, the $v$ velocity spectra at the 4 locations for the cases with a cross flow (Fig. 15 (d) and (f)) are nearly the same between Strouhal numbers of 2 and 6, whereas the 4 spectra for the baseline case (Fig. 15(b)) are all distinct. Although the details of the spectra are different, the levels are still generally similar to each other.

The spanwise correlations of $u$ and $v$ are examined in Figs. 16 and 17, respectively. In both $u$ and $v$, the correlations are higher for increasing $S / S_{\text {max }}$, which is behavior expected with the thickening of the shear layer. However, the increase is most rapid for $u$ between $S / S_{\max }=0.20$ and 0.45 . Comparing the results from the three simulations, the correlations appear quite similar. However, the coherence analysis of $u$ at $S / S_{\max }=0.81$ presented in Fig. 18(a) is much more discriminating. Although the baseline cases with different span lengths are in very good agreement, the two cases with cross flow show longer coherence lengths. Furthermore, the peaks in the $\left|\mathbf{V}_{\infty}\right|=0.17, \beta=45^{\circ}$ case would coincide with the others if the data were plotted against the unscaled frequency. The frequencies of these peaks coincide with those seen in the surface pressure spectra in Fig. 11(f) and coherence lengths in Fig. 14(a). Interestingly, even though both of the cases with cross flow exhibit these peaks in the coherence length of $u$, they are missing in the surface pressure spectra and coherence results for the $\left|\mathbf{V}_{\infty}\right|=0.17, \beta=45^{\circ}$ case. The coherence length analysis for $v$ is presented in Fig. 18(b). All three cases exhibit different levels although all of the curve shapes are somewhat similar in that they do not exhibit all the peaks observed in the $u$ velocity. 


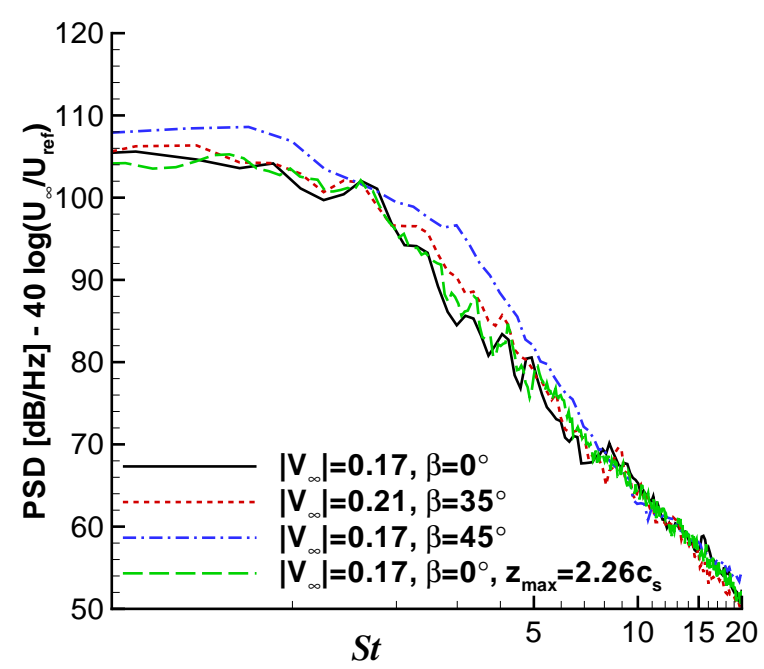

(a) Point 1

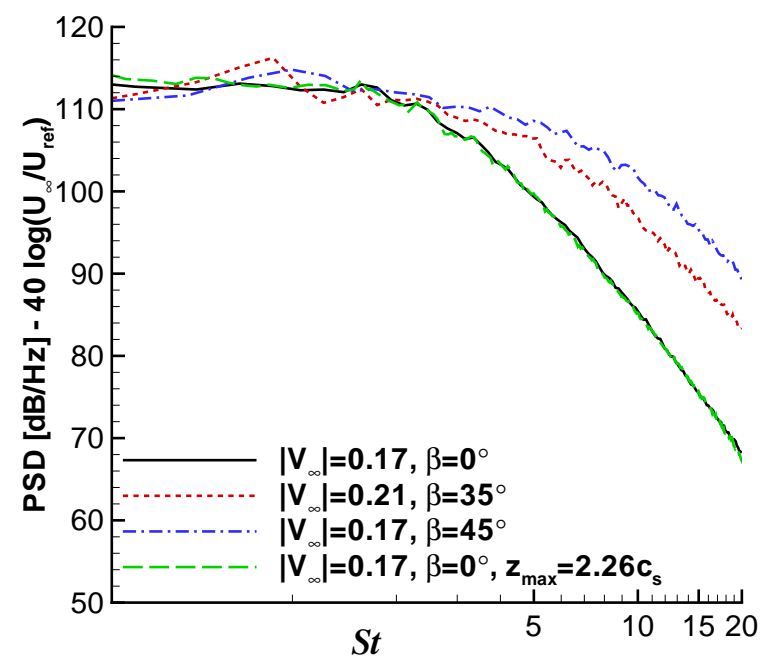

(c) Point 3

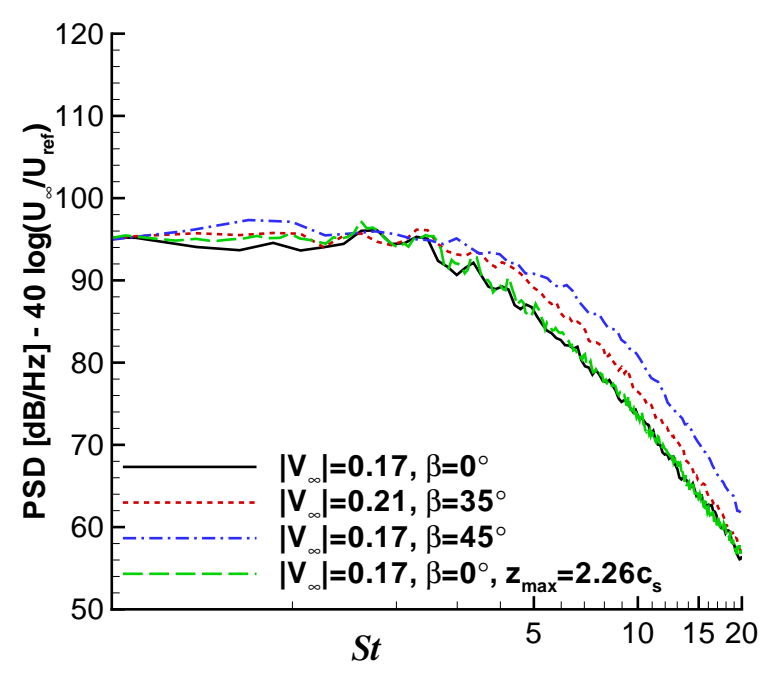

(e) Point 5

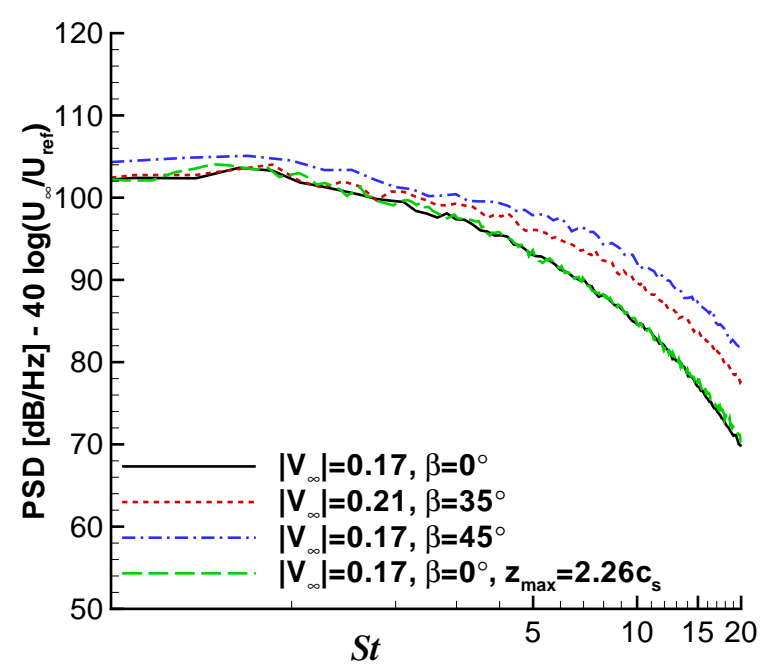

(b) Point 2

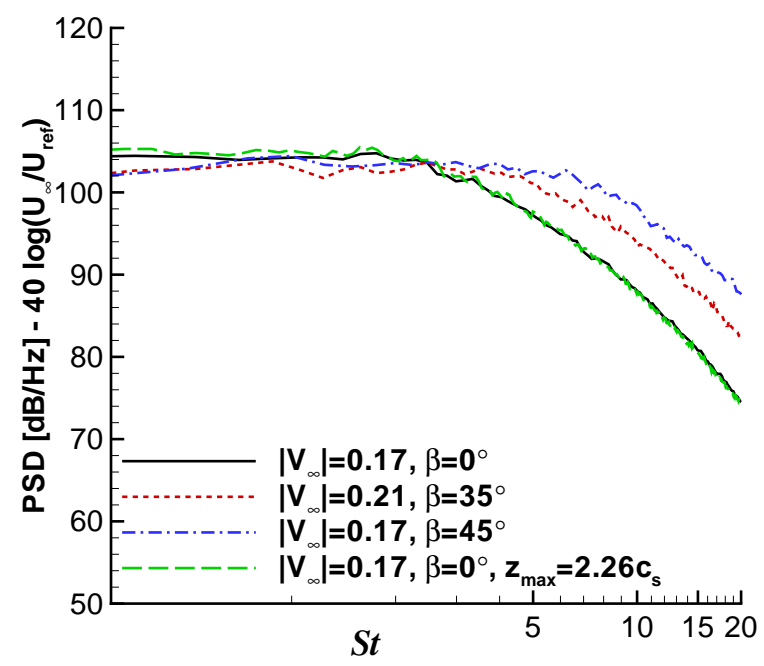

(d) Point 4

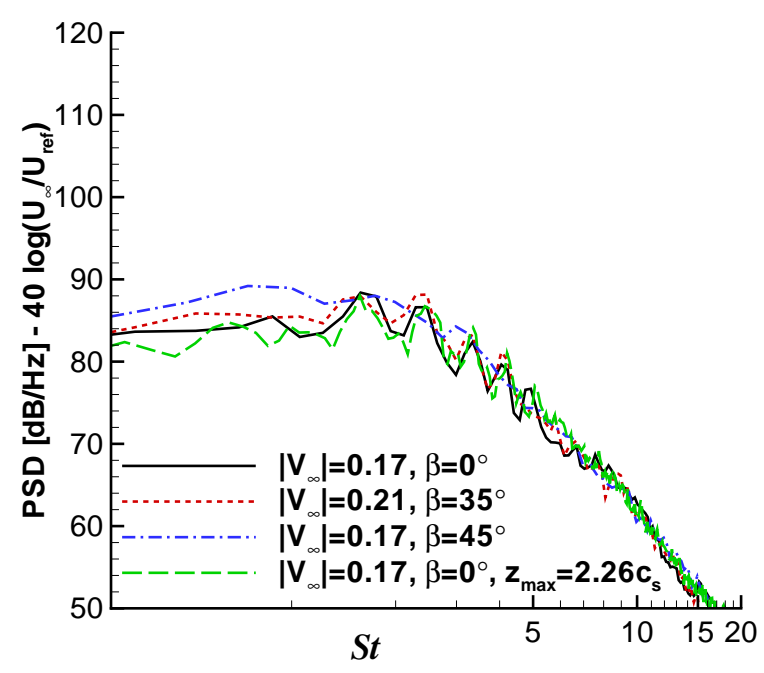

(f) Point 6

Figure 11. Power spectral density versus Strouhal number based on $U_{o}$ at the 6 points in Fig. 8. The reference velocity $U_{\text {ref }}=0.17$. 


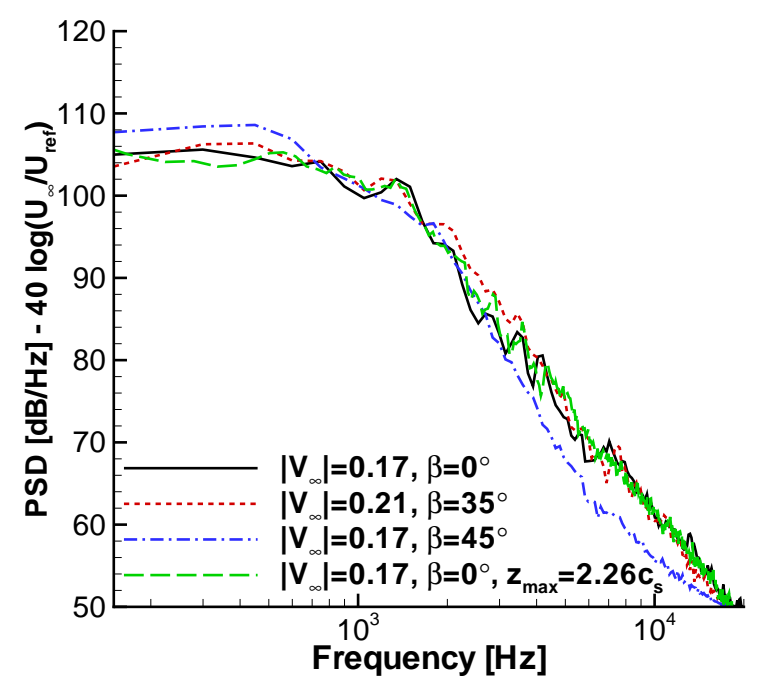

(a) Point 1

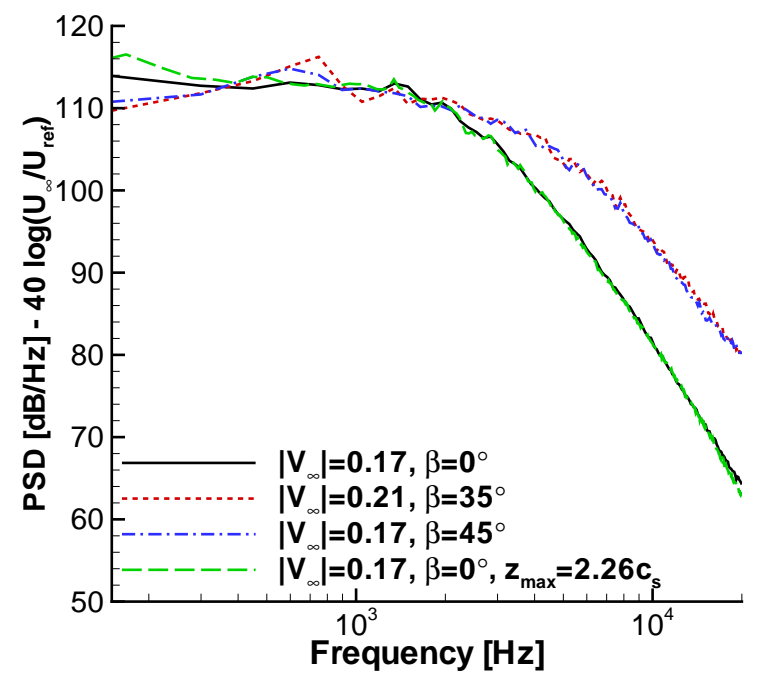

(c) Point 3

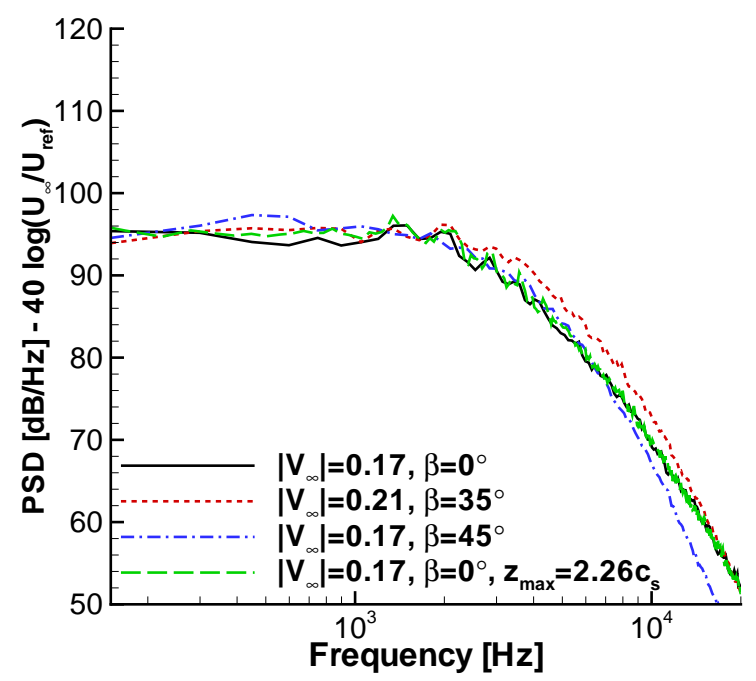

(e) Point 5

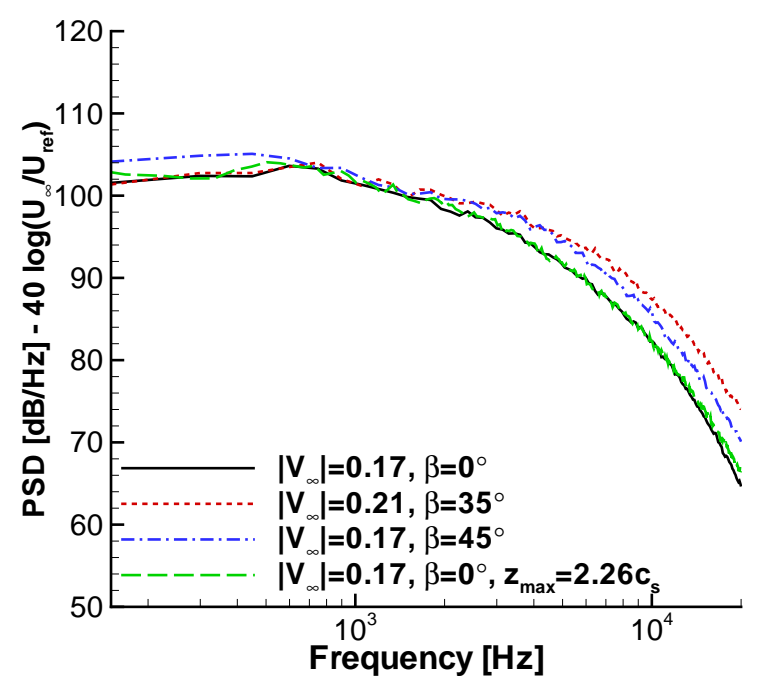

(b) Point 2

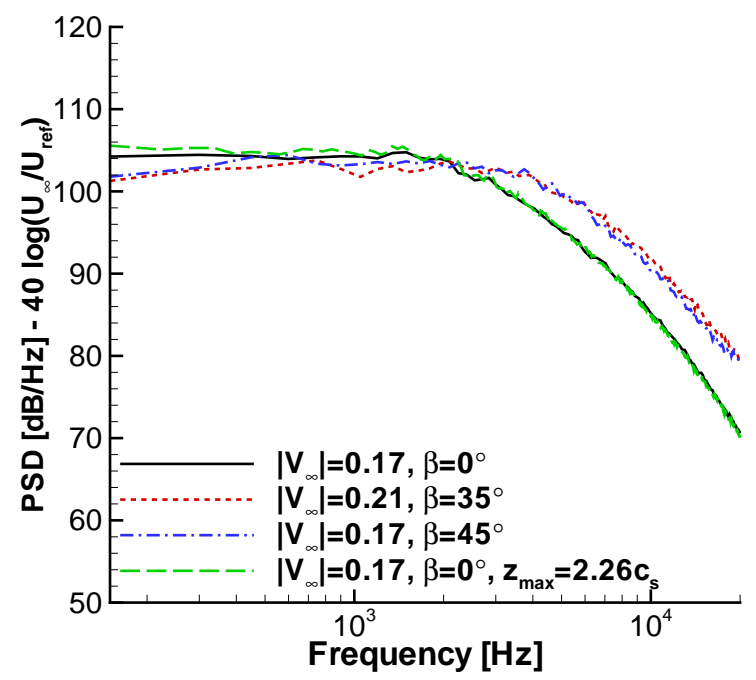

(d) Point 4

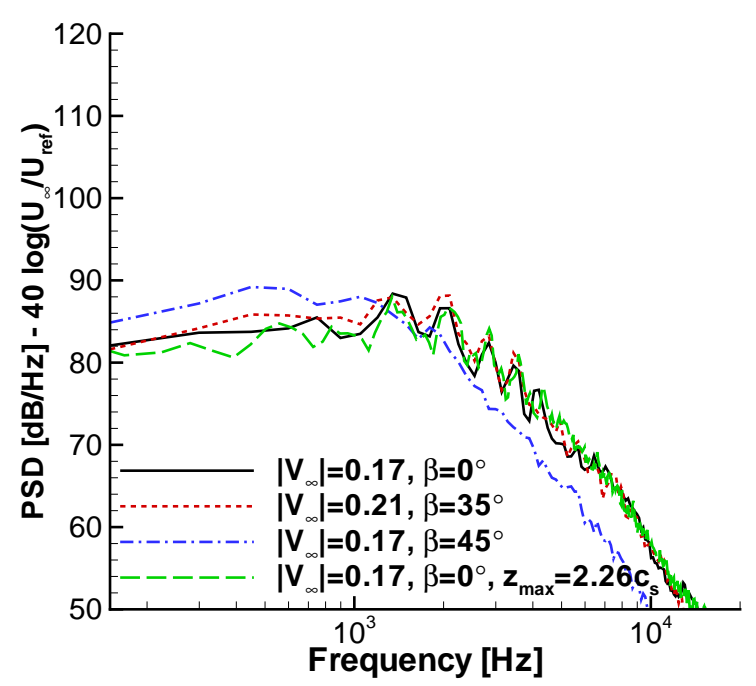

(f) Point 6

Figure 12. Power spectral density versus frequency at the 6 points in Fig. 8. The reference velocity $U_{\text {ref }}=0.17$. 


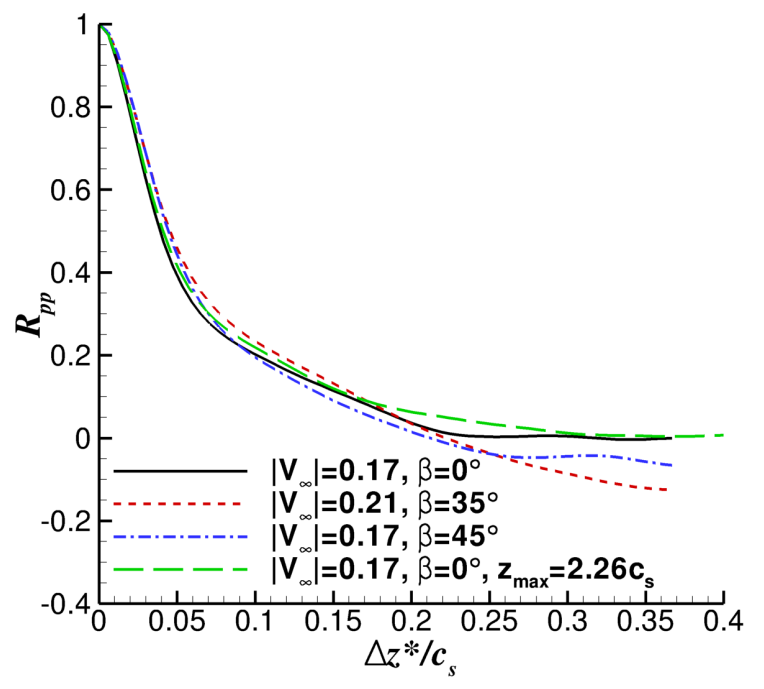

(a) Spanwise Correlation

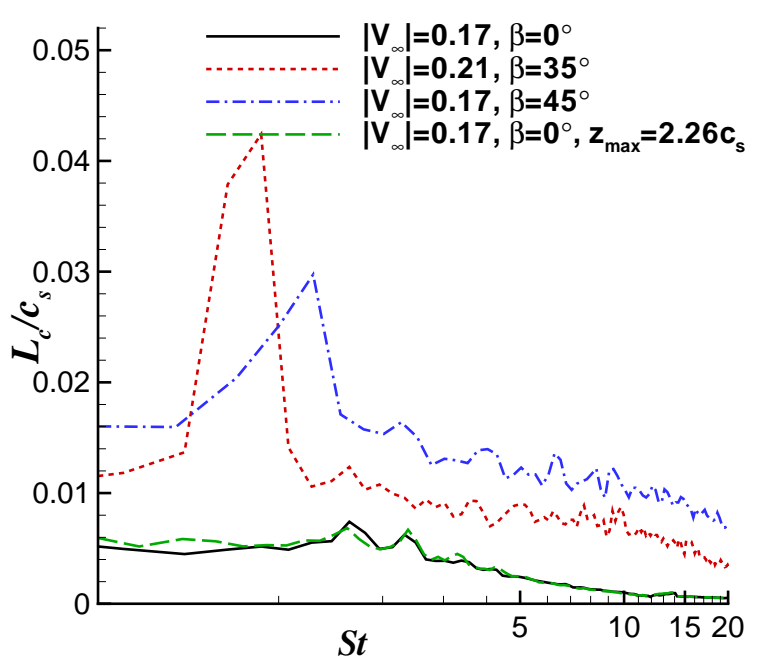

(b) Spanwise Coherence Length

Figure 13. Spanwise correlation and coherence length of $p$ at point 3 in Fig. 8.

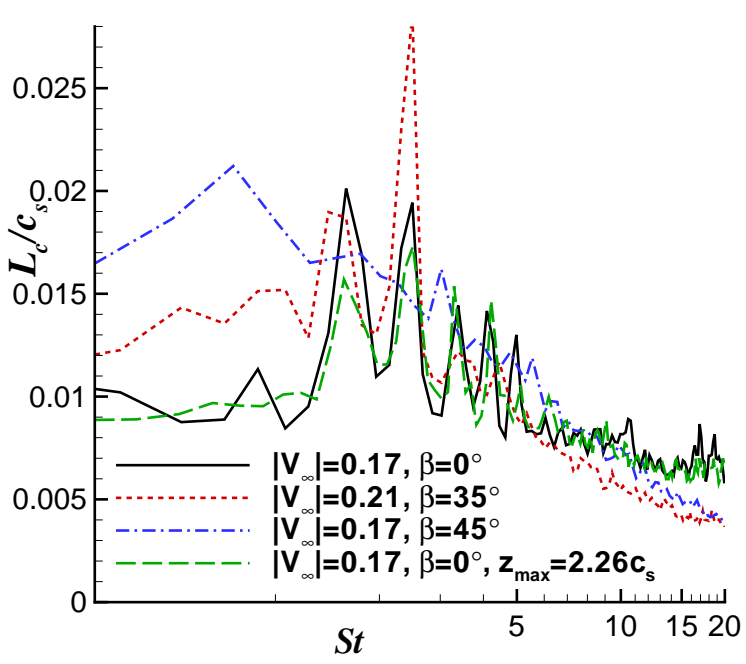

(a) Point 5

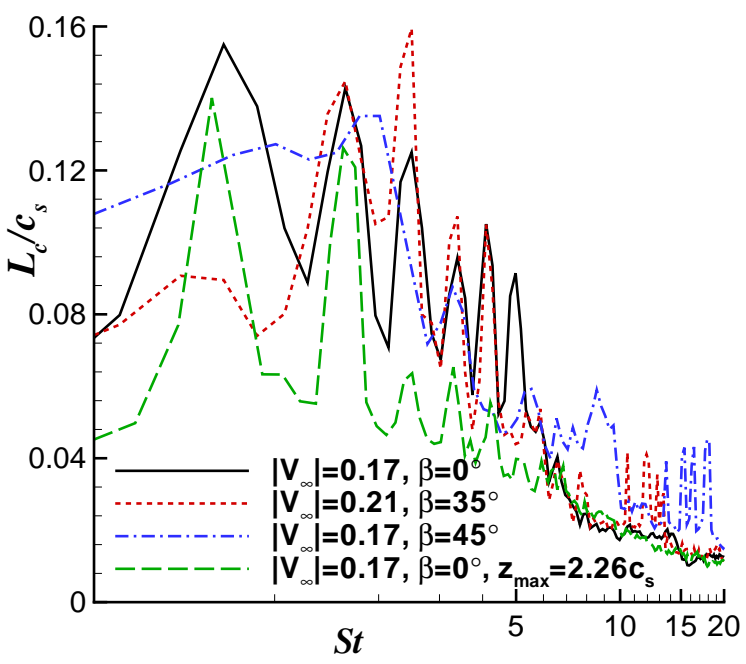

(b) Point 6

Figure 14. Spanwise coherence length of $p$ at points 5 and 6 in Fig. 8.

\section{Acoustics}

The far-field noise was calculated using the Ffowcs Williams-Hawkings (FW-H) equation ${ }^{27}$ solver described by Lockard. ${ }^{28}$ Unsteady flow data from the CFD calculations was recorded on the solid surfaces. The data was extracted over the full span used in the CFD calculation. However, only half of the spanwise data was used in the FW-H calculations to avoid artificial interference effects caused by the periodic nature of the simulations. Hence, the noise predictions are for a spanwise segment that is $37 \%$ of the slat chord. The temporal record of 35,000 time steps was divided into 6 separate segments with $50 \%$ overlap that were run through the FW-H solver, and the individual results were then averaged.

The effect of the spanwise flow on the radiated acoustics is examined in Fig. 19 which shows the directivity for observers located 10 chords from the slat trailing edge. The dimensionless pressure used in the figure is nondimensionalized by $\rho_{o} a_{o}^{2}$. The results from the longer span calculation were obtained by processing only the same spanwise extent of data as was available from the current simulations. The linear scale used in Fig. 19 does indicate some differences in the directivities from the 2 simulations with different span lengths, primarily above the slat. As was noted when the spanwise coherence was analyzed, the acoustic wavelength is quite long and even the longer span calculation does not completely capture the spanwise decorrelation in regions dominated by acoustic fluctuations. Nonetheless, the 


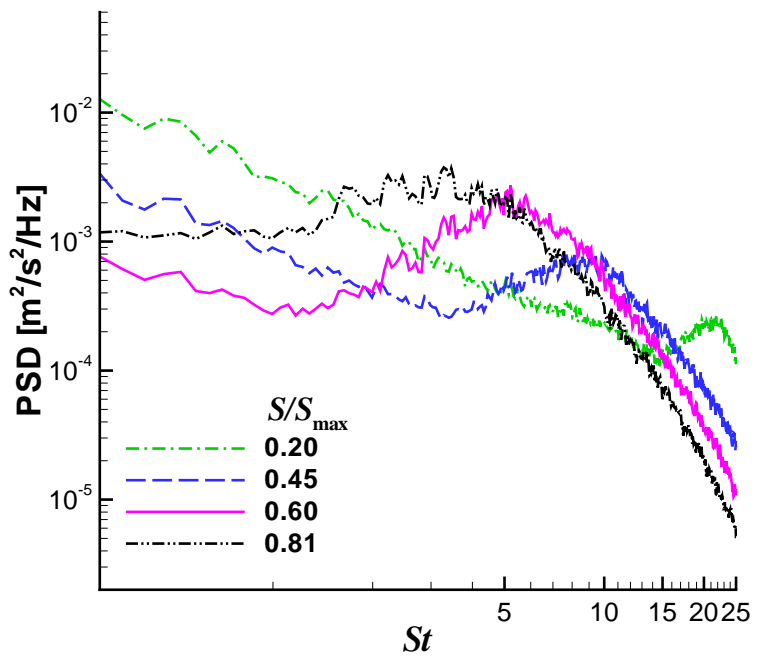

(a) $\left|\mathbf{V}_{\infty}\right|=0.17, \beta=0^{\circ}, G_{u u}$

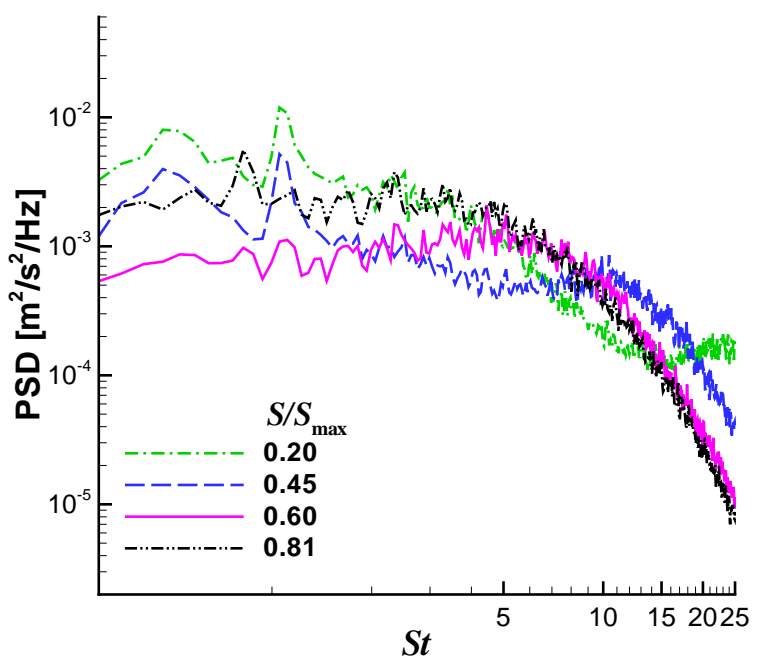

(c) $\left|\mathbf{V}_{\infty}\right|=0.21, \beta=35^{\circ}, G_{u u}$

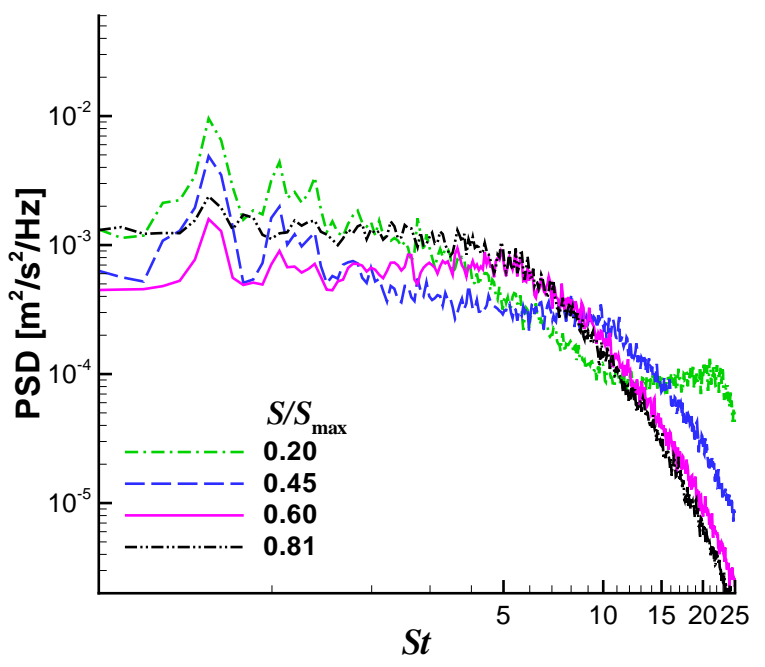

(e) $\left|\mathbf{V}_{\infty}\right|=0.17, \beta=45^{\circ}, G_{u u}$

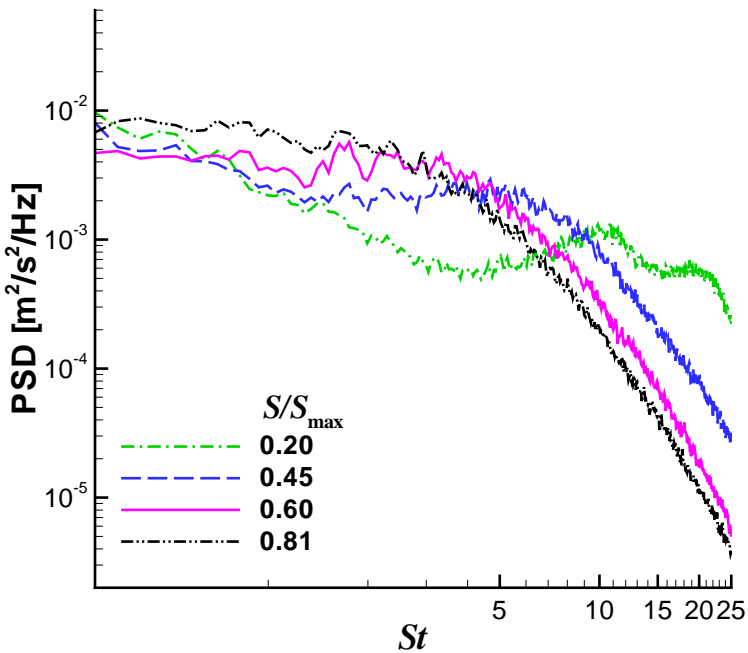

(b) $\left|\mathbf{V}_{\infty}\right|=0.17, \beta=0^{\circ}, G_{v v}$

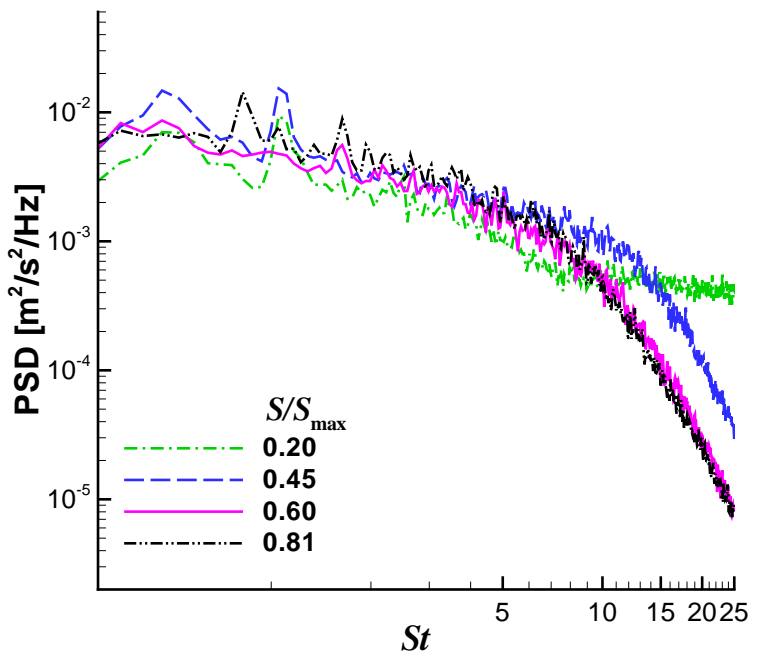

(d) $\left|\mathbf{V}_{\infty}\right|=0.21, \beta=35^{\circ}, G_{v v}$

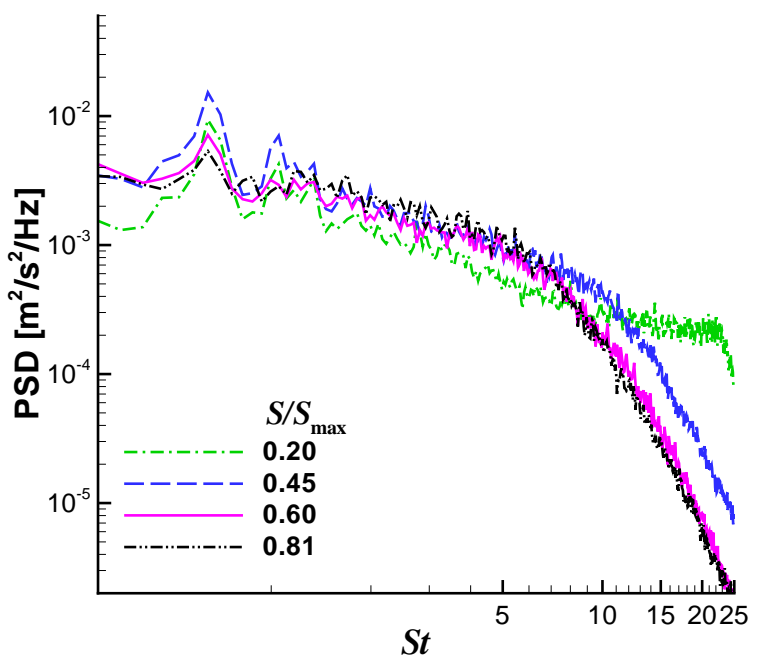

(f) $\left|\mathbf{V}_{\infty}\right|=0.17, \beta=45^{\circ}, G_{v v}$

Figure 15. Power spectral density of the $u$ and $v$ velocities versus Strouhal number at 4 locations along the trajectory of the slat cove shear layer shown in Fig. 8. 


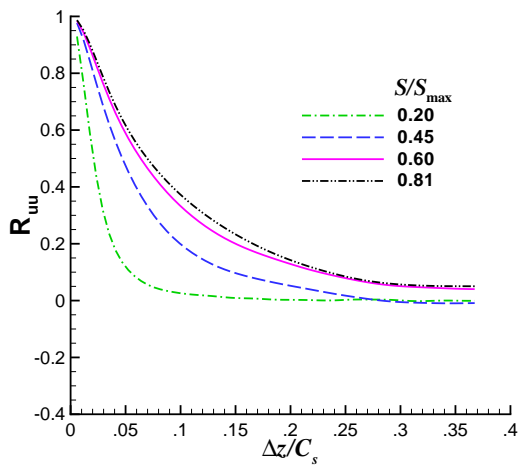

(a) $\left|\mathbf{V}_{\infty}\right|=0.17, \beta=0^{\circ}$

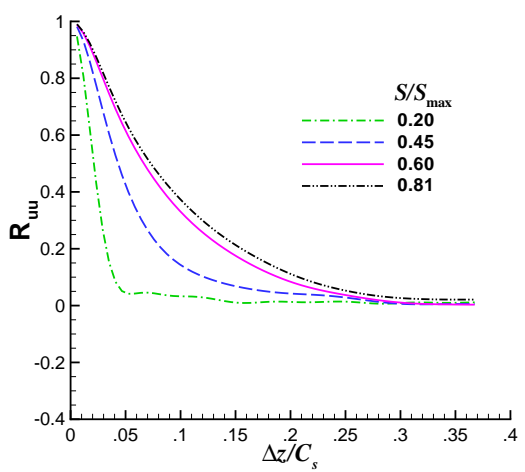

(b) $\left|\mathbf{V}_{\infty}\right|=0.21, \beta=35^{\circ}$

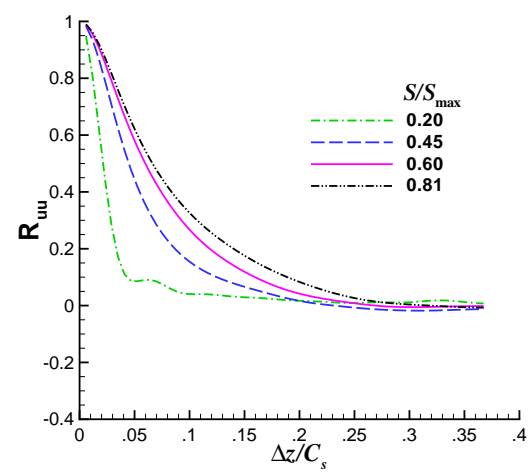

(c) $\left|\mathbf{V}_{\infty}\right|=0.17, \beta=45^{\circ}$

Figure 16. Spanwise correlation of the $u$ velocity.

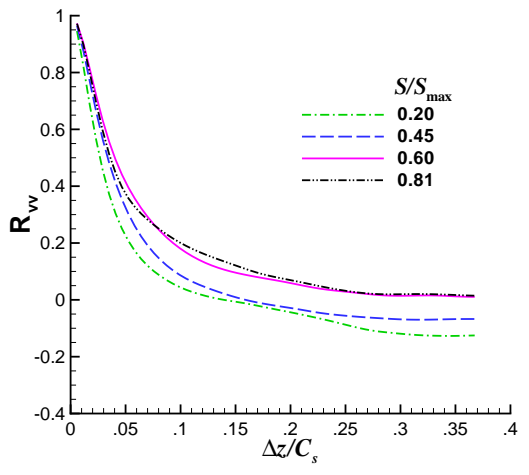

(a) $\left|\mathbf{V}_{\infty}\right|=0.17, \beta=0^{\circ}$

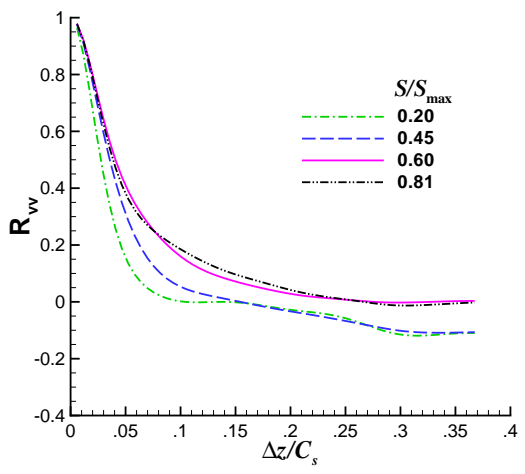

(b) $\left|\mathbf{V}_{\infty}\right|=0.21, \beta=35^{\circ}$

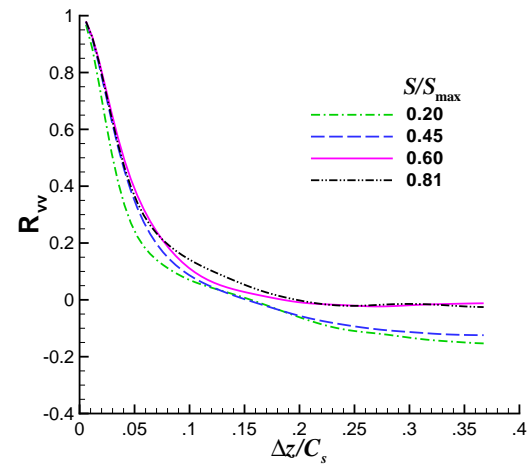

(c) $\left|\mathbf{V}_{\infty}\right|=0.17, \beta=45^{\circ}$

Figure 17. Spanwise correlation of the $v$ velocity.

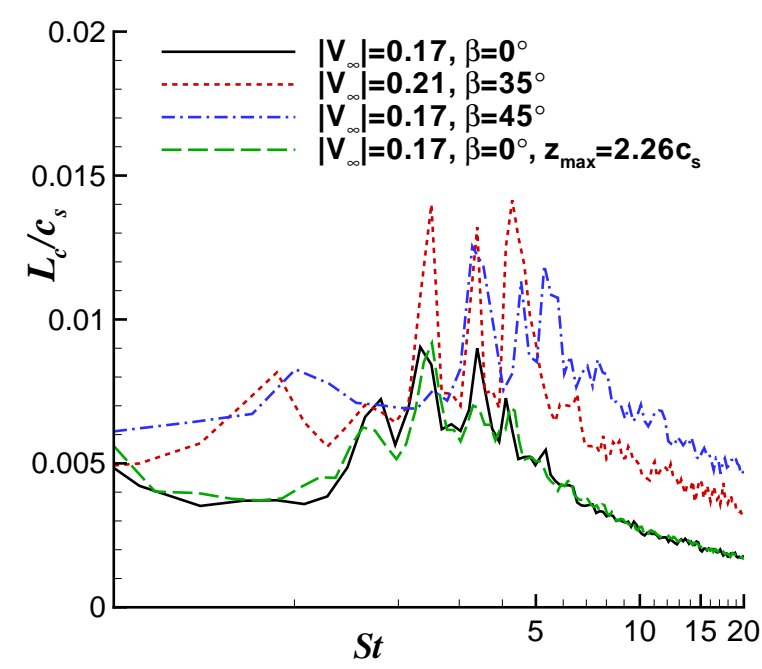

(a) $u$

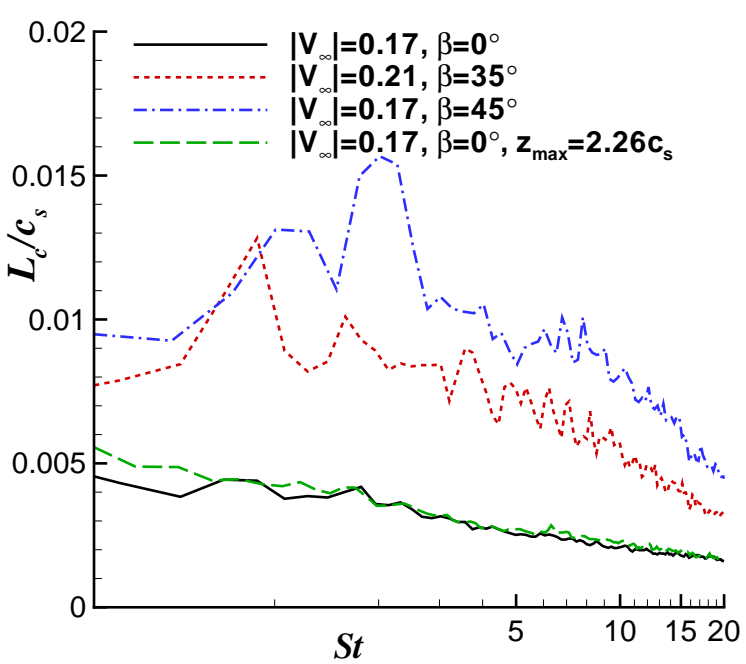

(b) $v$

Figure 18. Spanwise coherence length at $S / S_{\max }=\mathbf{0 . 8 1}$.

discrepancy is not that large and would hardly be noticeable on a decibel scale. However, the levels from the case with $\left|\mathbf{V}_{\infty}\right|=0.17, \beta=45^{\circ}$ are well below those of the other cases. In Fig. 19(b) the data are scaled assuming $p^{\prime 2} \sim U_{\infty}^{4}$ which produces a reasonable collapse of the cases with $\left|\mathbf{V}_{\infty}\right|=0.17, \beta=0^{\circ}$ and $\left|\mathbf{V}_{\infty}\right|=0.17, \beta=45^{\circ}$ except in the upstream direction. The magnitude of the fluctuations for $\left|\mathbf{V}_{\infty}\right|=0.21, \beta=35^{\circ}$ are still somewhat higher than for the other two cases as might have been expected as that case had the highest rms surface fluctuation levels when scaled similarly. Scaling based on the total velocity produces a very poor collapse with no agreement whatsoever. 


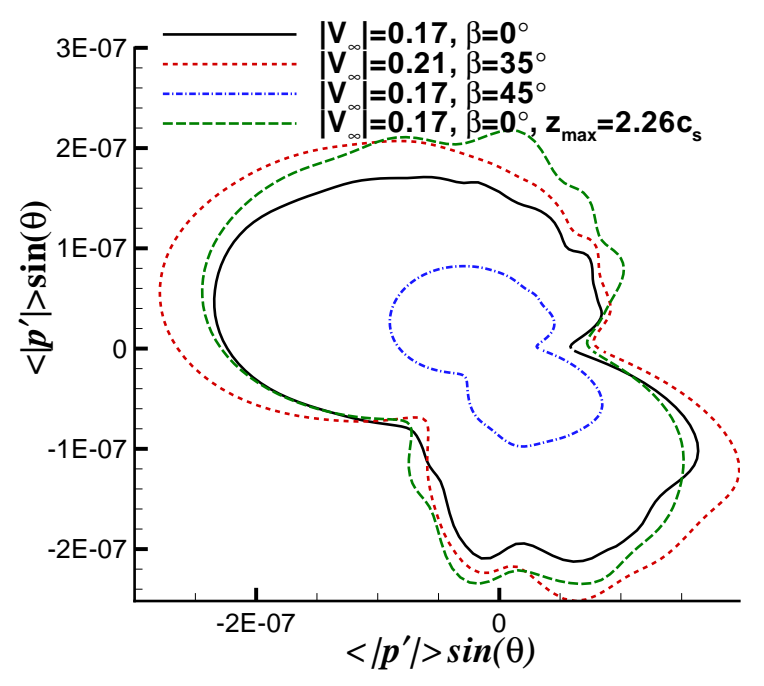

(a) Directivity

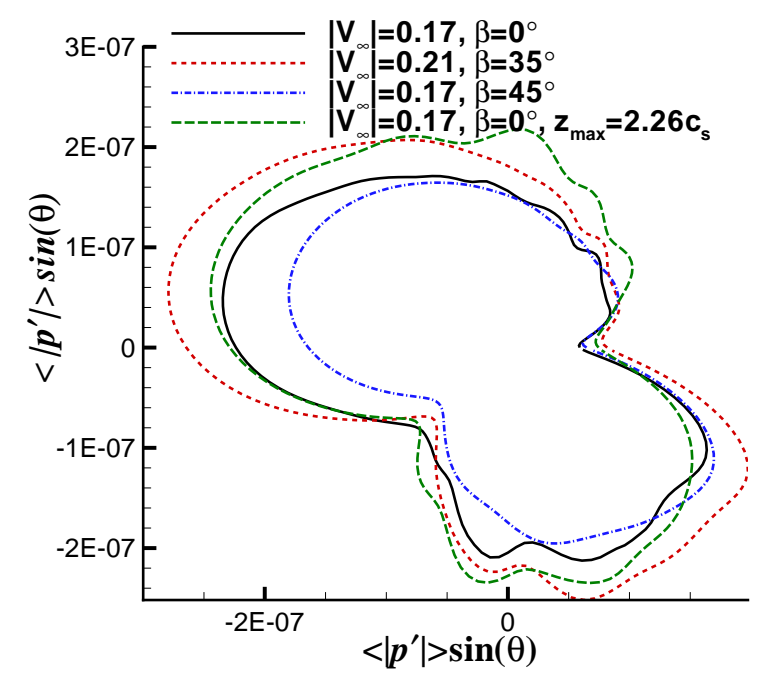

(b) Scaled directivity

Figure 19. FW-H predictions of the directivity. Observer is $\mathbf{1 0}$ chords from the slat trailing edge. Scaling performed assuming $p^{2} \sim U_{\infty}^{4}$ with $U_{\text {ref }}=0.17$.

The power spectral density of the pressure shown in Figure 20(a) is for an observer at a radius of 10 chords and an angle of $290^{\circ}$, which is near the peak in the lower arc of the directivity. The spectra have been smoothed to make visual inspection of the differences easier. Again, the result from the longer span calculation compares well with that from the current simulation. The primary discrepancy is in the peaks around $S t=2$ to 3 and for $S t>20$. The longer span solution exhibits similar increases in the levels at high frequencies at other angles. The behavior also appears to be intermittent as it only appears in the results from some of the 6 temporal segments used in the FW-H computations. Therefore, extrapolation of the high-frequency roll off using these results may be problematic.

The spectra also exhibit multiple, narrow band peaks, some of which correspond with the peaks observed in the coherence analysis of the shear layer velocity fluctuations and surface pressure. The $\left|\mathbf{V}_{\infty}\right|=0.21, \beta=35^{\circ}$ spectrum is very similar in shape to the baseline case, although the amplitude is slightly higher. The $\left|\mathbf{V}_{\infty}\right|=0.17, \beta=45^{\circ}$ spectrum does not exhibit all of the peaks, and the levels at high frequency are considerably above those of the other cases when using $p^{\prime 2} \sim U_{\infty}^{4}$ scaling and the Strouhal number for the abscissa. Figure 20(b) shows the spectra plotted against the unscaled frequency. A much better collapse is obtained at higher frequencies, but the agreement for low frequencies below $1000 \mathrm{~Hz}$ is not improved. The limited spanwise extent and short time records contribute to the discrepancies at low frequencies, so it is unclear whether the current datasets are meaningful in that range. 


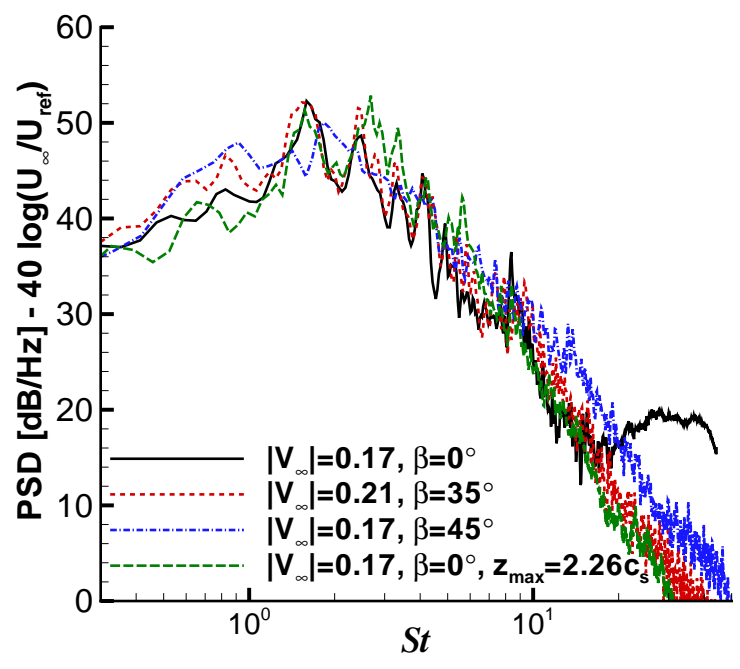

(a) Autospectra vs $S t$

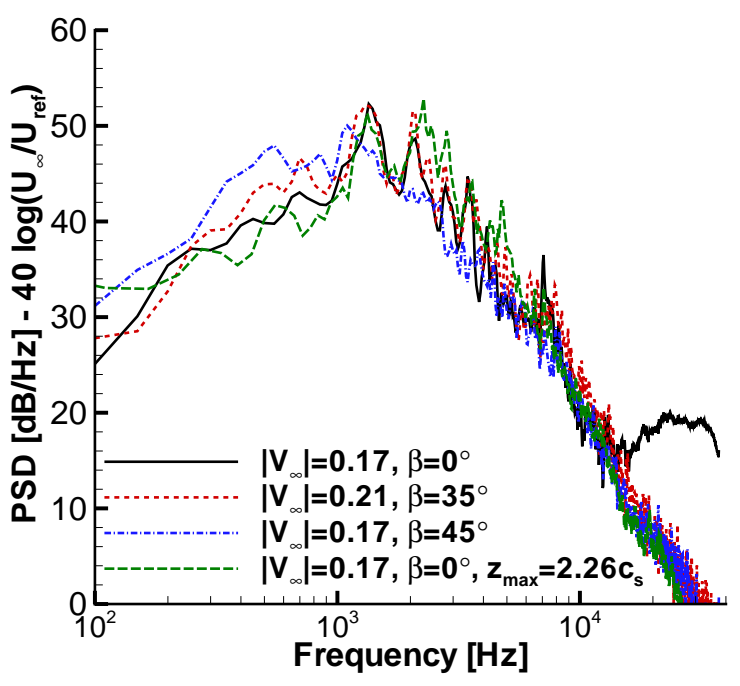

(b) Autospectra vs Frequency

Figure 20. FW-H predictions of the power spectral density at $290^{\circ}$. Spectra have been smoothed and scaled assuming $p^{\prime 2} \sim U_{\infty}^{4}$ with $U_{\text {ref }}=0.17$.

\section{Conclusions}

Three new simulations have been performed in an attempt to identify the effects of cross flow on slat noise. The baseline case is a repeat of a previous simulation with a longer span, and nearly all of the near-field comparisons with the results from the previous calculation demonstrate good agreement, indicating that an adequately long spanwise domain has been employed, at least for the metrics examined herein. Nonetheless, the corresponding acoustic predictions do exhibit some discrepancies. The much greater spanwise correlation in the acoustics that is not fully captured by the current nor previous simulations is the likely cause of the disagreement. However, even the acoustics comparisons only show some minor differences between the 2 sets of predictions.

The two cases with cross flow and the baseline exhibit similar behavior to each other in the slat cove region in terms of time-averaged quantities when the velocity normal to the leading edge is used to normalize the results. However, the spectral data only show agreement between the two computations with a cross flow, and this requires plotting against the unscaled frequency instead of the Strouhal number. The sound pressure level (SPL) of the radiated acoustics also appears to collapse better when using the unscaled frequency and an $M^{4}$ dependence. However, different parts of the frequency spectrum may have somewhat different scaling behavior as seen in Mendoza's measurements. ${ }^{6}$ Furthermore, the baseline case and one of the cases with a cross flow exhibit multiple discrete peaks in the spectra that are absent from the other cross-flow case. Because the Mach number and Reynolds numbers were varied simultaneously with the crossflow velocity, separating out the individual effects is difficult. Additional simulations individually varying the Mach number and Reynolds number should help to isolate how much of the current observations are a result of the cross flow. Nonetheless, the results seem to indicate that although the cross flow does alter the dynamics in the slat cove region, it does not have an order one influence on the radiated noise.

\section{Acknowledgments}

This work was supported by the NASA Fundamental Aeronautics Program's Subsonic Fixed-Wing Project. The authors gratefully acknowledge the assistance of Mr. M.R. Wiese from Analytical Services and Materials, Inc., who generated the computational grid used during the present study.

\section{References}

${ }^{1}$ Hayes, J. A., Horne, W. C., Soderman, P. T., and Bent, P. H., “Airframe Noise Characteristics of a 4.7\% Scale DC-10 Model,” AIAA Paper 1997-1594, 1997.

${ }^{2}$ Storms, B. L., Ross, J. C., Horne, W., Hayes, J., Dougherty, R. P., Underbrink, J. R., Scharpf, D. F., and Moriarty, P. J., "An Aeroacoustic Study of an Unswept Wing with a Three-Dimensional High Lift System," NASA TM 112222, February 1998.

${ }^{3}$ Dobrzynski, W., Nagakura, K., Gehlhar, B., and Buschbaum, A., "Airframe Noise Studies on Wings with Deployed High-Lift Devices," AIAA 
Paper 1998-2337, 1998.

${ }^{4}$ Storms, B. L., Hayes, J. A., Moriarty, P. J., and Ross, J. C., "Aeroacoustic Measurements of Slat Noise on a Three-Dimensional High-Lift System," AIAA Paper 1999-1957, 1999.

${ }^{5}$ Choudhari, M. M., Lockard, D. P., Macaraeg, M. G., Singer, B. A., Streett, C. L., Neubert, G. R., Stoker, R. W., Underbrink, J. R., Berkman, M. E., Khorrami, M. R., and Sadowski, S. S., "Aeroacoustic Experiments in the Langley Low-Turbulence Pressure Tunnel," NASA TM-211432, February 2002.

${ }^{6}$ Mendoza, F. and Brooks, T., "Aeroacoustic Measurements of a Wing/Slat Model," AIAA Paper 2002-2604, 2002.

${ }^{7}$ Chow, L. C., Mau, K., and Remy, H., "Landing Gears and High Lift Devices Airframe Noise Research,” AIAA Paper 2002-2408, 2002.

${ }^{8}$ Dobrzynski, W. and Pott-Pollenske, M., "Slat Noise Source Studies for Farfield Noise Prediction,” AIAA Paper 2001-02158, 2001.

${ }^{9}$ Guo, Y., Yamamoto, K., and Stoker, R., "Component Based Empirical Model for High-Lift System Noise Prediction," Journal of Aircraft, Vol. 40, No. 5, 2003, pp. 914-922.

${ }^{10}$ Guo, Y. and Joshi, M., "Noise Characteristics of Aircraft High-Lift Systems," AIAA Journal, Vol. 41, No. 7, 2003, pp. $1247-1256$.

${ }^{11}$ Khorrami, M. D., Berkman, M. E., and Choudhari, M., "Unsteady flow compuations of a slat with a blunt trailing edge," AIAA Journal, Vol. 38, No. 11, 2000, pp. 2050-2058.

${ }^{12}$ Singer, B. A., Lockard, D. P., and Brentner, K. S., "Computational Aeroacoustic Analysis of Slat Trailing-Edge Flow," AIAA Journal, Vol. 38, No. 9, 2000, pp. 1558-1564.

${ }^{13}$ Khorrami, M. R., Singer, B. A., and Berkman, M. E., "Time-accurate Simulations and Acoustic Analysis of Slat Free Shear Layer," AIAA Journal, Vol. 40, No. 7, 2002, pp. 1284-1291.

${ }^{14}$ Khorrami, M. R., Singer, B. A., and Lockard, D. P., “Time-accurate Simulations and Acoustic Analysis of Slat Free Shear Layer: Part II," AIAA Paper 2002-2579, 2002.

${ }^{15}$ Choudhari, M., Khorrami, M. R., Lockard, D. P., Atkins, H. L., and Lilley, G. M., "Slat Cove Noise Modeling: A Posteriori Analysis of Unsteady RANS Simulations," AIAA Paper 2002-2468, 2002.

${ }^{16}$ Khorrami, M. R., Choudhari, M. M., and Jenkins, L. M., "Characterization of Unsteady Flow Structures Near Leading-Edge Slat: Part II. 2-D Computations," AIAA Paper 2004-2802, 2004.

${ }^{17}$ Jenkins, L. M., Khorrami, M. R., and Choudhari, M. M., "Characterization of Unsteady Flow Structures Near Leading-Edge Slat: Part I. PIV Measurements," AIAA Paper 2004-2801, 2004.

${ }^{18}$ Choudhari, M. M. and Khorrami, M. R., "Effect of Three-Dimensional Shear-Layer Structures on Slat Cove Unsteadiness," AIAA Journal, Vol. 45, No. 9, 2007, pp. 2174-2186.

${ }^{19}$ Rakhshani, B. and Filippone, A., “Three-Dimensional CFD Analysis of Slat Noise,” AIAA Paper 2008-0015, 2008.

${ }^{20}$ Imamura, T., Enomoto, S., Yokokawa, Y., and Yamamoto, K., "Three-Dimensional Unsteady Flow Computations Around a Conventional Slat of High-Lift Devices," AIAA Journal, Vol. 46, No. 5, 2008, pp. 1045-1053.

${ }^{21}$ Klausmeyer, S. M. and Lin, J., "Comparative Results from a CFD Challenge Over a 2D Three-Element High-Lift Airfoill," NASA TM 112858, May 1997.

${ }^{22}$ Lockard, D. P. and Choudhari, M. M., "Noise Radiation from a Leading-Edge Slat," AIAA Paper 2009-3101, 2009.

${ }^{23}$ Imamura, T., Enomoto, S., Yokokawa, Y., and Yamamoto, K., "Simulation of the Broadband Noise from a Slat Using Zonal LES/RANS Hybrid Method," AIAA Paper 2007-0226, 2007.

${ }^{24}$ Rumsey, C. L., Biedron, R. T., and Thomas, J. L., “CFL3D: Its History and Some Recent Applications," NASA TM 112861, May 1997, presented at the Godonov's Method for Gas Dynamics Symposium, Ann Arbor, MI.

${ }^{25}$ Menter, F. R., "Two-equation Eddy-viscosity Turbulence Models for Engineering Applications," AIAA Journal, Vol. 32, No. 8, 1994, pp. 15981605.

${ }^{26} \mathrm{Li}$, G. and Lele, S., "Inviscid Instability of a Skewed Compressible Mixing Layer," Journal of Fluid Mechanics, Vol. 249, 1993 , pp. $441-463$.

${ }^{27}$ Ffowcs Williams, J. E. and Hawkings, D. L., "Sound generation by turbulence and surfaces in arbitrary motion," Philosophical Transactions of the Royal Society of London A, Vol. 342, 1969, pp. 264-321.

${ }^{28}$ Lockard, D. P., “A Comparison of Ffowcs Williams-Hawkings Solvers for Airframe Noise Applications," AIAA Paper 2002-2580, 2002. 